\title{
The 2017 Environmental Scan
}

\author{
National Council of State Boards of Nursing
}

\section{Imagining the Future: 2017 and Beyond}

he past year was momentous for science and technology. In May, the White House Office of Science and Technology Policy announced meetings and an interagency workgroup to probe opportunities for the use of artificial intelligence (Felten, 2016).

In October, the President hosted a landmark meeting, The White House Frontiers Conference (Holdren \& Smith, 2016). Scientists, economists, and workforce planners were among the participants asked to envision the country in 50 years and to project how robotics, artificial intelligence, and other technological breakthroughs will influence health care, space travel, communities and cities, climate change, and poverty. Also part of the White House initiative were two landmark reports: Preparing for the Future of Artificial Intelligence, from the Executive Office of the President, National Science, and Technology Council Committee on Technology (2016) and a companion document, The National Artificial Intelligence Research and Development Strategic Plan (National Science and Technology Council, Networking and Information Technology Research and Development Subcommittee, 2016). This White House agenda is a critical indicator of the rapidly developing innovations that will impact the nursing profession. Not only does nursing need to prepare for these changes, but nurses must be "the architects of change," which was the theme of the National Council of State Boards of Nursing's (NCSBN's) 2016 Annual Meeting.

In 2015, the United Nations published Transforming Our World: The 2030 Agenda for Sustainable Development, its 2030 agenda for sustainable development. To help regulators prepare for the future, NCSBN held a conference in October 2016, Regulation 2030, during which regulators and nursing leaders from around the world imagined the world in 2030 by addressing 25 emerging trends. The discussions resulted in concept maps that can be operationalized to accelerate progress and positive outcomes in nursing policy and regulation or can be used to manage risks and deter negative consequences. Immediately after Regulation 2030, NCSBN held the International Nurse Regulators Consortium, during which regulatory leaders from seven countries explored the evolution of concepts that inform public protection models. The keynote speaker, Dr. Daniel Susskind, highlighted essential themes from the book he recently coauthored, The Future of the Professions: How Technology will Transform the Work of Human Experts (2015), and led a discussion on how the work of professionals will change as machines become increasingly capable of doing that work, as medical monitoring devices are increasingly worn or imbedded in people and used in homes, and as people rely more on information from collective and Web-accessible platforms (Susskind \& Susskind, 2015).

Benjamin Franklin said, "By failing to prepare for the future, we prepare to fail." The first step in preparing for the future is to be fully aware of the present and to comprehend its implications for the future. The 2017 NCSBN Environmental Scan discusses the current state of nursing, explores the milieu in which regulators are immersed, and investigates the rapidly evolving innovations in health care, technology, politics, and society. It also describes where regulators need to focus their attention to stay ahead of change and to ensure a future that is safer than today.

\section{Nursing Workforce}

A bealth care workforce does not consist of a well-defined set of roles, but changes over time in response to many factors. It is influenced by the form of government of the society, definitions of health, social values, costs, the society's expectations for the health care system, and the political power of various players.

Ada Jacob Cox, PhD, RN, FAAN (1997)

Making accurate nursing workforce predictions beyond a few years requires knowing as much about emerging technology as knowing about data and trends. The process of making such predictions is complex and nuanced: one must look as far ahead as possible and determine if the economy and a multitude of other unpredictable factors will influence the data. In 2017, an additional question arises: will the profession be flexible enough to accommodate changes in personnel and staffing as well as the technology and innovation that are destined to influence the health care workforce of the future?

\section{U.S. Workforce}

NCSBN's National Nursing Database tracks the number of U.S. licensed nurses from 55 boards of nursing (BONs) daily. The database does not include numbers from the Oklahoma, Hawaii, and Louisiana-PN BONs. As of September 2016, the database revealed 3,880,565 registered nurses (RNs) and 913,453 licensed practical nurses and licensed vocational nurses (LPN/VNs) in the United States (NCSBN, 2016a). The most recent Occupational Employment Statistics data indicate that 2,687,310 RNs and 695,610 LPN/VNs were employed 
in the United States as of May 2015 (U.S. Bureau of Labor Statistics, 2016). These statistics show that 2015 had the largest number of employed nurses in more than a decade. However, as Figure 1 illustrates, the RN workforce has increased, and the LPN/VN workforce has decreased since 2012.

\section{FIGURE 1}

\section{Employed RNs and LPN/VNs in the United States}
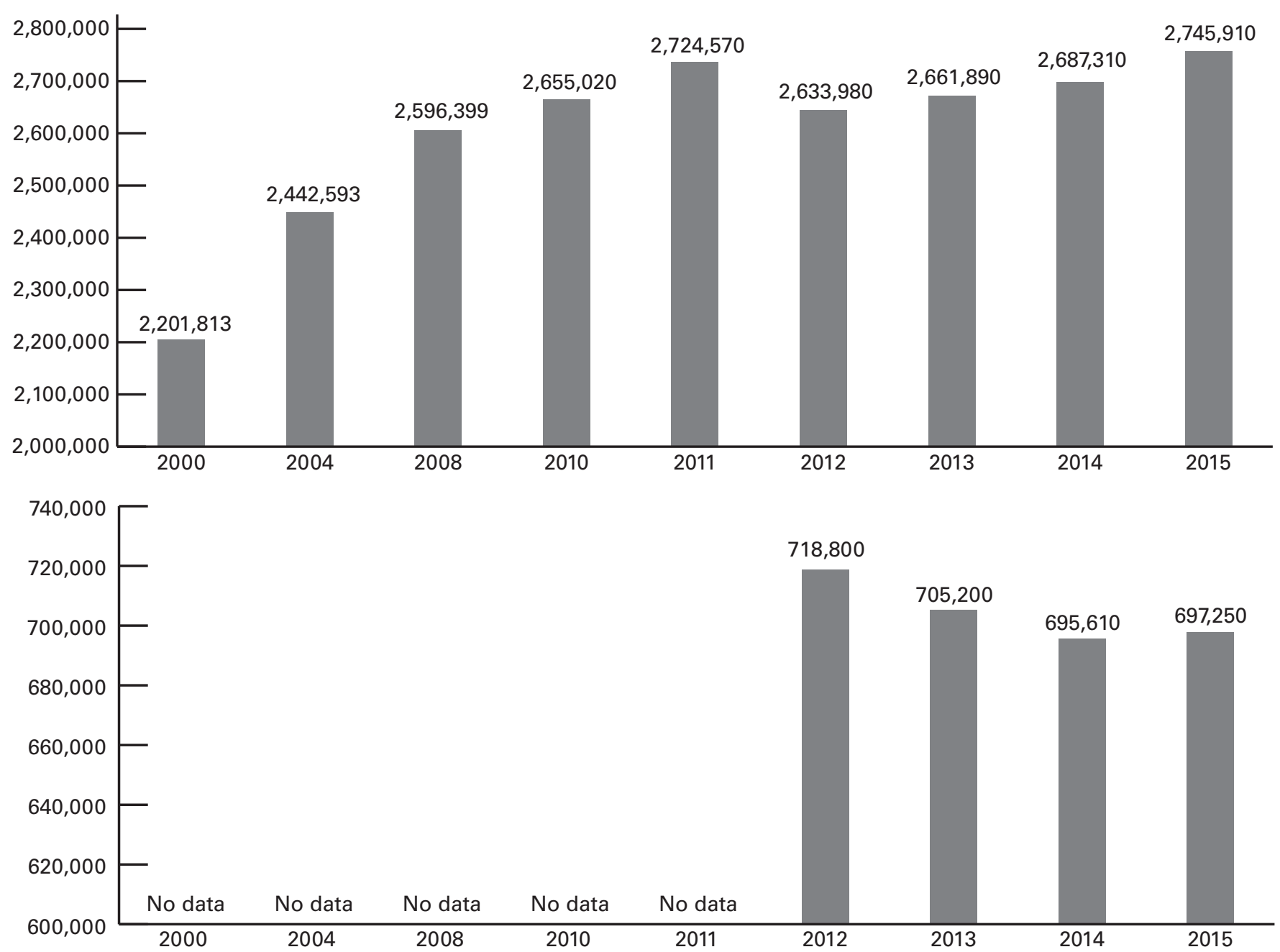

Note. The 2010-2015 statistics are from the semiannual Occupational Employment Statistics survey published by the U.S. Bureau of Labor Statistics (2016). The 2000, 2004, and 2008 statistics are from the U.S. Department of Health and Human Services Health Resources Services Administration's National Sample Survey of Registered Nurses (2010). LPN/VN = licensed practical nurse and licensed vocational nurse; RN = registered nurse.

The distribution of employed RNs varies substantially by state, as shown in Figure 2. California, Nevada, Utah, Oklahoma, and Georgia have the fewest RNs employed per capita: 600 to 700 nurses per every 100,000 people (U.S. Bureau of Labor Statistics, 2016; U.S. Census Bureau, 2016). Alaska, Hawaii, Colorado, Maine, Nevada, Oregon, Rhode Island, and Utah have the fewest LPN/VNs employed per capita: 0 to $100 \mathrm{LPN} / \mathrm{VNs}$ per every 100,000 people. 


\section{FIGURE 2}

\section{Employed RNs and LPN/VNs per 100,000 People by State}

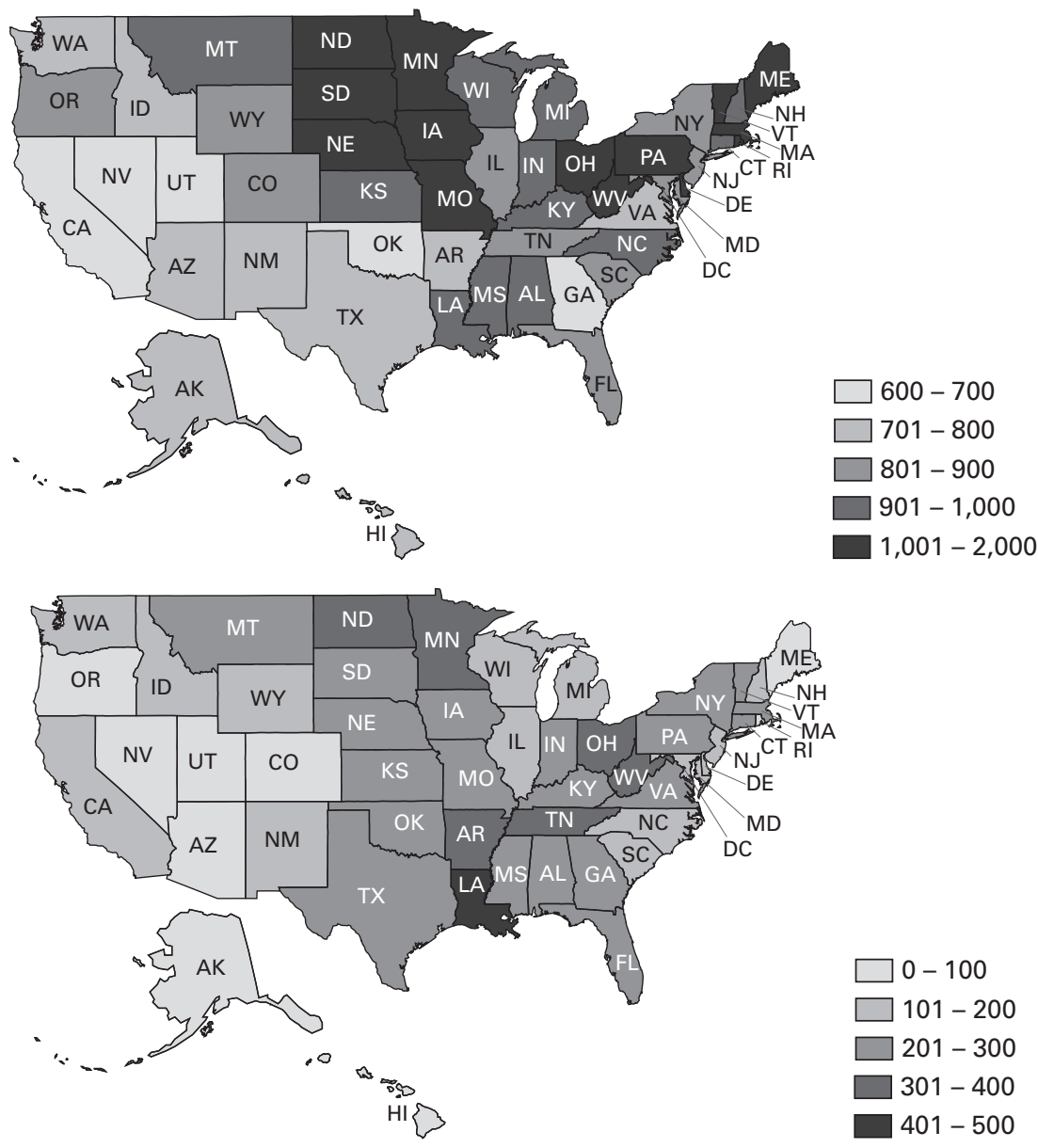

Note. State-by-state depiction of the ratio of employed registered nurses (RNs) and licensed practical nurses and licensed vocational nurses (LPN/VNs) per 100,000 population as of May 2015 (U.S. Bureau of Labor Statistics, 2016; U.S. Census Bureau, 2016).

Over the past year, the supply and demand of nurses has been a topic of much discussion. The maps in Figure 2 demonstrate a state-level snapshot of the supply of employed nurses. However, for those studying and monitoring the nursing workforce, regional differences within states are often the main concern. For instance, California has one of the lowest employed nurse-to-population ratios; however, within the state, city centers such as San Francisco may have high nurse-to-population ratios, whereas rural areas may have low nurse-to-population ratios. In-state regional nurse employment numbers are available for download from the U.S. Bureau of Labor Statistics (2016).

Nurse employment settings have slowly shifted over the past few years, possibly driven by health care costs. The most expensive places to deliver care are inpatient facilities and emergency departments (National Center for Health Statistics, 2016). Care traditionally delivered in those settings will increasingly be provided at home or in the community. Moving care to the community or the home is likely to produce large savings and a shift in workforce distribution. Urgent care clinics employing advanced practice registered nurses (APRNs) are projected to grow to 12,000 by 2019 and deliver simple services at a $72 \%$ savings over emergency departments (Rechtoris, 2016). The home care market is projected to expand to $\$ 157$ billion by 2022 (Elsevier, 2016). The growth of these nonhospital settings will affect the nursing workforce, especially APRNs.

In the United States, more than 250,000 APRNs practice in four roles: certified nurse practitioner, certified registered nurse anesthetist (CRNA), certified nurse midwife (CNM), and clinical nurse specialist (CNS). In 2014, the number of certified nurse practitioners was 222,000 (American Association of Nurse Practitioners, 2016). CRNAs currently number more than 45,000 (Phillips, 2017). In 2015, the American Midwifery Certification Board reported 11,210 CNMs. The number of CNSs is more difficult to estimate because they were not recognized in some states until recently and still are not recognized in a few states (Newland, 2016). The overwhelming 
majority of APRNs prescribe (95.2\%) and, on average, have been in practice more than 12 years. Ninety-six percent of APRNs have graduate degrees, and 83\% hold advanced certification in primary care (American Association of Nurse Practitioners, 2016).

APRNs, who are growing in number, are well positioned to step further into the primary care arena (Academy of Medical-Surgical Nurses et al., 2016). When allowed to practice to the full extent of their education and training, they care for the vulnerable in designated health professional shortage areas, both urban and rural (Xue, Ye, Brewer, \& Spetz, 2016). In a large national sample of ambulatory patients, Barnes and others found that APRNs have a $13 \%$ greater likelihood of working in primary care in states that allow full-practice authority and that they are $23 \%$ more likely to be caring for Medicaid patients if the state allows full reimbursement for their care (2016).

\section{New Graduate Employment and Loan Burden}

As shown in Table 1, the trend for new graduates finding employment has improved since 2012. In 2012, only $51 \%$ of new graduates had a job less than 1 month after graduation. In 2016, 75\% did. After 6 months, 97\% had jobs, compared with 86\% in 2012.

\section{TABLE 1}

\section{New Graduate RNs Employed After Graduation}

\begin{tabular}{|c|c|c|c|c|c|}
\hline & $2012(n=4,110)$ & $2013(n=6,121)$ & & & $2016(n=3,901)$ \\
\hline & Employed (\%) & Employed (\%) & Employed (\%) & Employed (\%) & Employed (\%) \\
\hline$>1$ month (graduated in summer) & 51 & 56 & 62 & 71 & 75 \\
\hline$>4$ months (graduated in spring) & 71 & 76 & 78 & 85 & 88 \\
\hline$>6$ months (graduated in previous year) & 86 & 87 & 88 & 93 & 97 \\
\hline
\end{tabular}

Data for 2012-2015 from previous scans. Data for 2016 from NSNA (2016). RN = registered nurse.

In 2016, the American Association of Colleges of Nursing (AACN, 2016) conducted a brief online survey of 743 deans of nursing, asking about employment rates for new nurses immediately after graduation and 4 to 6 months after graduation. The survey, which had a response rate of $77.5 \%$, found that the average job-offer rate at graduation for entry-level nurses with a Bachelor of Science in nursing (BSN) degree was 70\%; for entry-level nurses with a Master of Science in nursing, or MSN, degree, the rate was $74 \%$. The survey also revealed that $92 \%$ of entry-level BSN nurses had job offers 4 to 6 months after graduation. These results mirrored those of the National Student Nurses' Association (NSNA) survey (2016). The employment rates varied across regions: the South had the highest rate (77\%), and the West had the lowest (66\%). A comparison of these findings with those of a survey conducted by the National Association of Colleges and Employers (2015) $(n=39,950)$ of new college graduates across disciplines indicates that nursing is doing well. The National Association of Colleges and Employers found that only $50.6 \%$ of their respondents had job offers at graduation, a percentage that was the highest since the recession.

As shown in Table 2, BSN graduates continue to be employed as RNs at a greater percentage (92.73\%) than graduates of associate degree (i.e., ADN) programs (89.59\%) or accelerated BSN programs (86.08\%) (NSNA, 2016). Similarly, in the 2016 annual survey of new graduate employment (AACN, 2016), deans of baccalaureate programs $(n=576)$ reported that $54 \%$ of hospitals and other health care settings require new hires to have a BSN degree—a $6.6 \%$ increase from 2015. Further, the deans reported that $97.9 \%$ of employers express a strong preference for hiring BSN program graduates. Likely, the recommendation in the Institute of Medicine's (IOM's) report, Future of Nursing (2011), to increase the percentage of BSN-educated nurses, as well as research findings indicating that increased ratios of BSN-educated nurses positively affect patient safety, has influenced employers to prefer BSN-educated nurses to ADN-educated nurses. The reason accelerated BSN graduates are being hired at lower percentages is not as clear. Brandt, Boellaard, and Zorn (2015) suggest that employers may have an inaccurate perception that accelerated BSN programs are abbreviated and that the content is trimmed. As the nursing shortage plays out, these hiring differences may dissolve. 
TABLE 2

\section{New Graduate RN Employment by Program}

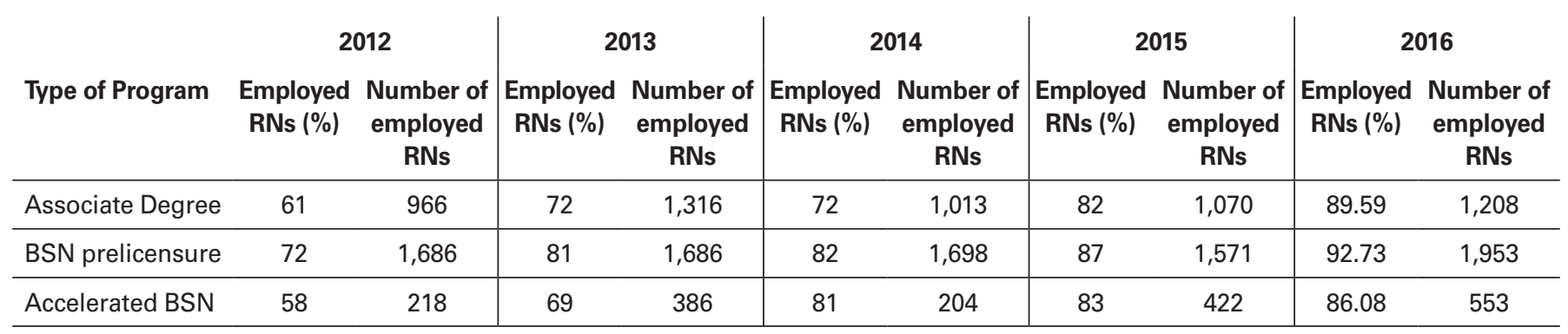

Note. $\mathrm{BSN}=$ Bachelor of Science in nursing; $\mathrm{RN}=$ registered nurse.

NSNA (2016) also looked at a 2-year trend of employment percentages by type of institution (Table 3). These data illustrate that graduates of private not-for-profit institutions have the highest employment percentages, followed by public institutions and then private for-profit institutions. All three types of institutions increased their employment percentages from 2015 to 2016.

\section{TABLE 3}

\section{Employment Rates of Graduates of For-Profit Versus Not-for-Profit and Pubic Institutions}

\begin{tabular}{|c|c|c|c|c|}
\hline & Employed as RN & Public & Private (Non-for-Profit) & Private (For-Profit) \\
\hline \multirow{2}{*}{$\begin{array}{l}2015 \\
n=3,548\end{array}$} & Yes & $84.6 \%(1,930)$ & $86.1 \%(709)$ & $82.24 \%(366)$ \\
\hline & No & $15.4 \%(351)$ & $13.9 \%(114)$ & $17.0 \%(78)$ \\
\hline $\begin{array}{l}2016 \\
n=3,901\end{array}$ & No & $10.44 \%(264)$ & $9.23 \%(77)$ & $12.08 \%(65)$ \\
\hline
\end{tabular}

\section{The Future of Nursing Workforce Supply and Demand}

Discussion continues regarding the supply and demand of nurses. Does a surplus exist? Or a shortage? The answers depend on whether the interpretation is based on a macro or micro view of the nursing workforce. A national view, a state-level view, or an in-state regional view may result in different conclusions. Nuances of the nursing workforce can only be understood by interpreting both the macro and micro views. For instance, if a surplus exists at the state level but a shortage exists at an in-state regional level, the data suggest recruiting more practicing nurses and simultaneously adding more nurses to the educational pipeline in the affected region.

Another common nursing workforce question is: Will enough nurses will be available to make up for the looming baby boom retirements? Auerbach, Buerhaus, and Staiger (2015) conducted a study that forecasted the size and age distribution of the nursing workforce through 2030. The researchers projected that annual retirements from nursing will accelerate from 20,000 per year a decade ago to 80,000 per year in the next decade. However, projections also revealed that the entry of new RNs into the workforce could counteract this acceleration. Of course, the projections are contingent on the entry into nursing remaining at its current high rate. In addition, the researchers compared their results with demand estimates by the U.S. Department of Health and Human Services (HHS) Health Resources and Services Agency and noted that their estimate of the future RN supply fell slightly below the agency's estimates.

The retirement rate of older nurses and the entry rate of newer nurses are just two variables that fluctuate. Additional factors that may impact future workforce demands include global economic downturns or upturns, changes in health care laws, and new methods and modes of health care delivery, including better preventive health care that keeps patients out of the hospital.

Advances in technology may have the greatest impact on the nursing workforce, making the current use of workforce data and modeling obsolete. In Japan, where the elderly outnumbers the labor force, robotic nurses are projected to save the country $\$ 21$ billion per year in health care costs. Engineers have already created robotic nurses that look and speak like human beings. These machines are performing nursing skills, including helping patients transfer, taking vital signs, and administering medications. They also perform telehealth, serving as an intermediate between physician and patient (Masui, 2016; Leiber, 2016). In the United States, Duke Pratt School of Engineering and the School of Nursing has invented a telerobotic intelligent nursing assistant, or TRINA, a mechanical robot nurse that takes vital signs and delivers medications to patients. The scientists at Duke have greater plans for TRINA and others like it. They envision robotics playing a role in the care of patients with highly infectious diseases such as Ebola (Bridges, 2016). 
What do changes in technology mean for the nursing workforce? Presently, the impact on nursing is uncertain; however, the types of nursing skills required in the future may be drastically different than those of today. Perhaps, the future will require fewer nurses but have increased demands for highly technically skilled nurses and direct-care nurses for aging patients (Josiah Macy, Jr. Foundation, 2016).

\section{Implications for Regulators}

As machines become more sophisticated and take over some responsibilities of humans, questions emerge about the role of regulators in keeping patients safe. Today, robots cannot reason through ethical dilemmas, make decisions weighing options, or consider a person's feelings or a family situation. However, delegation may be cast in a new light, with nurses delegating tasks once performed by them or assistive personnel to robots. Questions also emerge about who will oversee the robotic workforce and be accountable when things go wrong. These are a few challenging issues of the near future.

\section{Workforce Data Collection}

As new workforce modeling techniques are developed and new ways of estimating workforce needs emerge, NCSBN works with BONs to build a national workforce database of the future. The long-term vision is to have workforce data and statistics on the entire U.S. nursing workforce. The database already provides aggregate data that reflects local, regional, state, and national workforce characteristics. However, only 17 BONs currently provide data to NCSBN's nursing workforce database: Arizona, Arkansas, Connecticut, Georgia, Iowa, Kentucky, Maine, Minnesota, Mississippi, Nevada, New Hampshire, North Carolina, Ohio, South Dakota, Texas, Washington, and Wyoming. Data are collected at the time of licensure renewal. Questions are based on the National Forum for Nursing Workforce Centers Minimal Dataset, and data are stored in Nursys ${ }^{\circledR}$, NCSBN's nurse licensure and disciplinary database. BONs currently participating in the project transmit the data to Nursys and can later access their aggregate data and run real-time workforce reports for their state.

\section{Education}

To keep pace with the changing environment of health care, educators must continually monitor the pulse of nursing in the United States. Students must be prepared to enter a challenging workforce that holds high expectations for performance and advanced delivery of care.

How should nurses be prepared for the future? The IOM's 2010 Future of Nursing recommended an $80 \%$ BSN workforce by the year 2020 (IOM, 2011). This goal inspired the formation of nursing coalitions around the country that developed strategies to meet it, and in subsequent years, the number of BSN graduates has risen in the United States.

In 2016, Altman, Butler, and Shern assessed the progress of the Future of Nursing recommendations and concluded that, between 2010 and 2014, the number of employed nurses with a BSN degree increased from $49 \%$ to $51 \%$. Further, they found that the number of baccalaureate programs has increased faster than associate-degree or diploma programs. Buerhaus, Auerbach, and Staiger (2016) published comparable data. They analyzed the most recent findings from the Integrated Postsecondary Education Data System and observed that in 2002, 893 ADN programs and 667 BSN programs existed. In 2014, the number of ADN programs increased to 1,245 (28\%), and the number of BSN programs increased to $1,078(38 \%)$.

Current data, however, suggest that the overall number of RN programs may be beginning to taper. The number of RN programs increased from 1,571 in 2003 to 2,410 in 2015, but, in 2016, the number decreased to 2,402 (See Figure 3). These data do not include the RN-to-BSN programs (NCSBN, 2016a).

\section{FIGURE 3}

\section{Number of RN Prelicensure Programs in the United States}

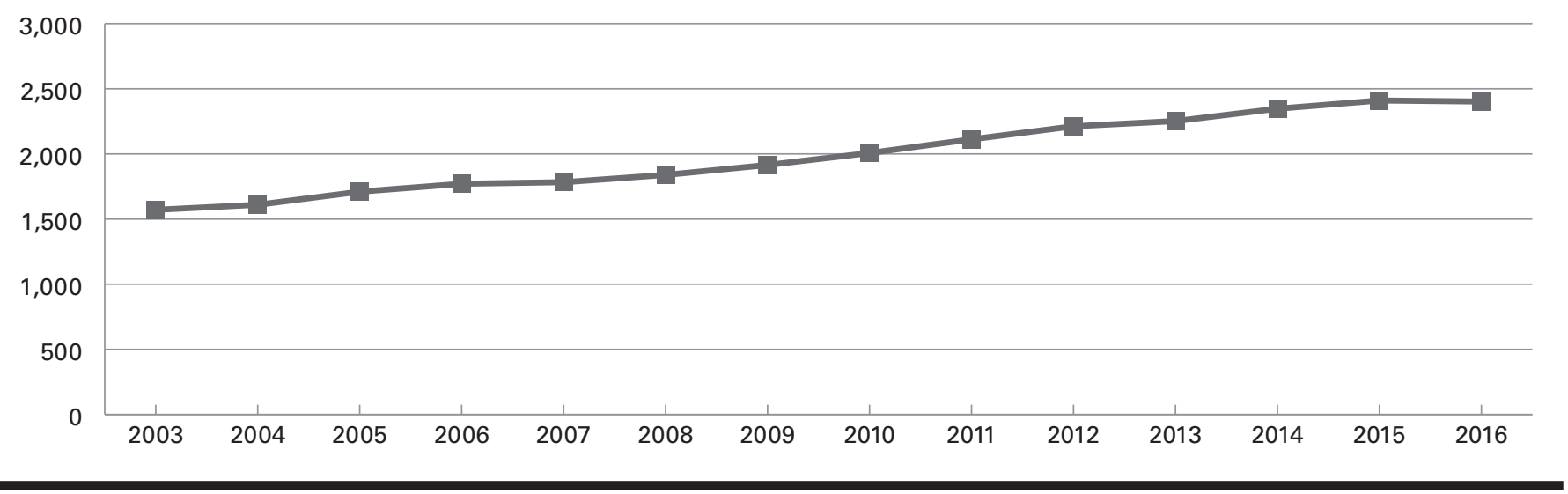


Funded by the Robert Wood Johnson Foundation to develop a more highly educated nursing workforce, the Academic Progression in Nursing (APIN) program was created by the Tri-Council for Nursing — an alliance of the AACN, the American Nurses Association, the American Organization of Nurse Executives, and the National League for Nursing. Grants provided by the program have been instrumental in advancing strategies and models that promote the advancement of nursing education and employment. More than $\$ 9$ million has been invested in the APIN program, and nine states-California, Hawaii, Massachusetts, Montana, New Mexico, New York, North Carolina, Texas, and Washington-have received grants. Some APIN states have reported an increased BSN workforce compared with the national average, although outcomes vary widely from state to state. APIN identified the following five models to allow a more seamless advancement of education (Altman et al., 2016):

- Baccalaureate completion programs in community colleges: Currently, 22 states allow community colleges to confer baccalaureate degrees, although only seven states allow community colleges to administer nursing degrees; of those seven, only Florida and Washington have a structured path.

- State or regionally shared competency models or outcomes-based curriculum: The prelicensure nursing curriculum is not standardized, but the model is intended to achieve standardized outcomes.

- Accelerated RN-to-MSN programs: These programs offer ADN-educated nurses a streamlined way to obtain an advanced degree. Some programs allow students to "step out" with a BSN degree.

- Shared statewide or regional curriculum: Universities and community colleges form partnerships and collaborate on a shared curriculum or curricular components, allowing students to seamlessly transition from an associate degree to a baccalaureate program, without repeating coursework.

- Shared baccalaureate curriculum: Community colleges and universities work together to establish a baccalaureate curriculum; students can take courses at community colleges and universities, but they can take the National Council Licensure Examination only after completing the baccalaureate degree.

Although the Future of Nursing recommendation to increase the percentage of BSN-educated nurses has likely contributed to the increase in RN-to-BSN programs (Altman et al., 2016), an unintended consequence is the variability of the programs, particularly because, in many states, programs do not have regulatory oversight by BONs. Only 12 BONs approve (that is, have the authority to regulate) RN-to-BSN programs (NCSBN, 2015), and national nursing accreditation of RN-to-BSN programs is not required. Flexible prerequisites and programs without prerequisites in the sciences or humanities raise concern (Buerhaus, Auerbach, \& Staiger, 2014; Hooper, McEwen, \& Mancini, 2013). Additionally, BONs report a lack of uniformity in clinical experience for some RN-to-BSN programs, specifically experience in leadership, evidence-based nursing practice, or community-population health. Experts call for the development of standardized RN-to-BSN competencies (McEwen, 2015).

\section{Faculty}

Despite the overall rise in the number of BSN graduates, the impending shortage of faculty members and other issues may significantly impact the future of nursing education. In 2016, NCSBN used a systematic process to develop a prioritized list of concerns that regulators had about the current state of nursing education. Based on a literature review, a BON survey, and input from nursing education subject matter experts and BON executives, five concerns emerged as priorities. The primary concern was the faculty shortage.

Each year since 2000, the AACN has reported data on the status of the faculty in nursing programs across the United States. The 2016-17 Faculty Vacancy Survey (Li, Kennedy, \& Fang, 2016) was sent to 965 baccalaureate nursing schools; the overall response rate was $85.7 \%$. As shown in Table 4, although nursing schools have been obtaining more budgeted positions, the vacancy rate has stayed about the same as has the rate of filled faculty positions, perhaps indicating that schools are expanding their programs to educate more BSN graduates. In 2015, the mean faculty vacancies per school nearly doubled, but in 2016, the number reverted to previous levels. However, the range of faculty vacancies rose sharply in 2016, which may have implications for the future. Interestingly, the number of schools that need faculty members but have no vacancies is on the rise, whereas the number of schools that do not need additional faculty members is also increasing. Regional variations may cause this circumstance. 
TABLE 4

\section{Nursing Program Full-Time Faculty: Trends (2011-2016)}

\begin{tabular}{|c|c|c|c|c|c|c|}
\hline ( $n=821$ schools responding) & 2011 & 2012 & 2013 & 2014 & 2015 & 2016 \\
\hline Budgeted faculty positions & 14,166 & 15,574 & 16,444 & 18,010 & 18,511 & 19,830 \\
\hline Number of faculty vacancies (vacancy rate) & $\begin{array}{l}1,088 \\
(7.7 \%)\end{array}$ & $\begin{array}{l}1,181 \\
(7.5 \%)\end{array}$ & $\begin{array}{c}1,358 \\
(8.3 \%)\end{array}$ & $\begin{array}{c}1,236 \\
(6.9 \%)\end{array}$ & $\begin{array}{l}1,328 \\
(7.1 \%)\end{array}$ & $\begin{array}{l}1,567 \\
(7.9 \%)\end{array}$ \\
\hline Number of filled faculty positions (filled rate) & $\begin{array}{l}13,078 \\
(92.3 \%)\end{array}$ & $\begin{array}{c}14,393 \\
(92.4 \%)\end{array}$ & $\begin{array}{l}15,086 \\
(91.7 \%)\end{array}$ & $\begin{array}{c}16,774 \\
(93.1 \%)\end{array}$ & $\begin{array}{c}17,183 \\
(92.9 \%)\end{array}$ & $\begin{array}{c}18,263 \\
(92.1 \%)\end{array}$ \\
\hline Range of faculty vacancies & $1-16$ & $1-20$ & $1-29$ & $1-20$ & $1-26$ & $1-36$ \\
\hline $\begin{array}{l}\text { Number of schools with no faculty vacancies, but need } \\
\text { additional faculty }\end{array}$ & 104 & 103 & 98 & 124 & 130 & 133 \\
\hline $\begin{array}{l}\text { Number of schools with no faculty vacancies, do not need } \\
\text { additional faculty }\end{array}$ & 145 & 182 & 168 & 187 & 182 & 220 \\
\hline
\end{tabular}

The top reasons that schools are unable to hire new faculty members are similar to those reported previously $(n=133)$ :

- Insufficient funds to hire new faculty members $(63.9 \%)$

- Unwillingness of administration to commit to additional full-time positions (49.6\%)

- Inability to recruit qualified faculty members because of competition for jobs in other marketplaces (38.3\%)

- Qualified applicants for faculty positions are not available in the geographic area (24.1\%).

The most critical issues schools face when recruiting faculty members are also similar to those reported previously:

- Noncompetitive salaries (33.5\%)

- Limited pool of doctorate-prepared faculty members (24\%)

- Inability to find faculty members with the right specialty mix $(21 \%)$

- Inability to find faculty members willing and able to conduct research $(5.4 \%)$

- Inability to find faculty members willing and able to teach clinical courses $(5 \%)$

- High faculty workload $(3.5 \%)$.

A recent study by Yedidia (2016) reports on the Robert Wood Johnson Foundation's Evaluating Innovations in Nursing Education initiative, which supports research on the faculty workforce and generates evidence on promising interventions to address shortages. One reason for the insufficient numbers of nursing educators is that many nurses choose the faculty career path later in life, and nursing educators retire earlier, resulting in shorter faculty careers. Oermann, Lynn, and Agger (2016) surveyed nursing program administrators from around the United States and found differences in current faculty needs. In contrast to ADN programs, BSN programs are recruiting doctorate-prepared educators. Although educators with a Doctorate of Nursing Practice, or DNP, and those with a PhD are hired, the former group faces challenges related to scholarship expectations and decreased opportunities for tenure-track appointments. Difficulties in faculty recruitment in general include low salary and geographic location. Salary considerations also influence an institution's ability to retain APRNs.

Yedidia (2016) also discusses the establishment of the National Nursing Education Research Network as a pilot organized by nurse leaders. Pilot schools agreed to survey their students and faculty members annually on a uniform set of items, creating a database of standardized data. These data allow educators to make evidence-based decisions about faculty recruitment, including establishing benchmarks for faculty workload, formulating faculty staffing plans, and engaging in strategic planning.

Some states have developed comprehensive strategies to enhance the nurse educator workforce. One such initiative, Nurses for Wisconsin (Young et al., 2016), received a University of Wisconsin Incentive Grant to accelerate the preparation of nurse educators by supporting their enrollment in DNP or PhD programs. This initiative provided pre- and postdoctoral fellowships and recruited educators with a loan repayment program. In exchange, educators agreed to remain in the University of Wisconsin system for 3 years.

\section{Innovative Teaching Strategies}

Changes in curriculum and pedagogy mean that nursing education a few years from now may bear little resemblance to nursing education today. For example, the recent move toward competency-based education is attracting interest for the future assessment of the profession. 
More educators are using the flipped classroom model. Intended to increase student engagement, this model assigns content as homework that was traditionally presented in a classroom, and class time is used for more active learning, such as case studies, laboratories, or simulation, under the guidance of a faculty member. Presti's (2016) recently published integrative literature review of the flipped classroom model suggests that it may improve learning; however, the reviewed studies were weak in measuring the outcomes, a gap that may be filled by future research. One interesting finding was that student satisfaction may be inversely related to improved performance. That is, although examination grades improved, the students disliked the new method of teaching.

Kindergarten through 12th-grade educators may the most proficient at telling nurse educators how the students of the future will best be able to learn. These pioneers are using new teaching methods to educate the nursing students of the future, including gamification. Interactive and engaging, gamification increases learning retention (Brull \& Finlayson, 2016). Cook (2013) reports that game mechanics can increase the retention rate as much as 10 times compared with lecture. Moreover, gamification is available via computers, tablets, and smartphones. As with simulation, gaming provides a safe environment for failure: if the simulated patient expires, the student can just reboot with an increased knowledge of what went wrong (Brull \& Finlayson, 2016).

Gamification also holds many possibilities for testing. One Canadian province has already developed a jurisprudence examination based on gamification strategies (Lemermeyer \& Sadeksy, 2016), and this approach is only the beginning of what the future holds for this technology.

Distance education is playing a growing role in nursing education. Wood (2016) suggests that because students can learn from a distance, educators can supervise clinical experiences from remote sites. Although the literature is scant on this topic, such remote supervision has the potential to relieve some of the faculty shortage. Wood acknowledges that some educators are better suited for remote work, and the cost benefit for the individual and the institution should be considered. Although this concept may gain traction in the future as institutions continue to grapple with budget and personnel challenges, the success of this model requires addressing the implications of moving to a less traditional model regarding teaching loads, expectations, tenure, and other factors.

As patients use more digital health mechanisms for everything from chronic disease management to wellness care, nurses will face new expectations for technological competence. Soon, nurses may manage more device alerts than actual patients, may need skills to interpret streaming data as opposed to episodic in-person assessment data, and may interact with patients via cyber partnerships and Web-based communications more than via face-to-face interactions (Schulmeister, 2016; Triantafyllopoulous, Korvesis, Mporas, \& Megalooikonomou, 2016; Wilson, 2016). Nursing education programs will need to equip nurses with the skills and initial competencies for the digital health age (Hopia, Punna, Laitinen, \& Latvala, 2015; Schulmeister, 2016).

Aided by experiences with high-fidelity simulation laboratories, distance learning, and personal technology use, many nurses graduate with a high level of technological skill, (Metcalfe, Jonas-Dwyer, Saunders, \& Dugmore, 2015; Wilson, 2016). However, schools of nursing will be challenged to keep pace with the rate of technological advancements in practice settings. They must ensure faculty competence and the availability of equipment to train students on innovative technologies. In the digital health age, nurses will be designing and developing innovative technologies to improve patient care, engaging in research on wearable devices and patient-centered outcomes, and using data science skills to harness the big data from devices in research (Baquapuri, Wajdan, Kutafina, Misgeld, \& Jonas, 2016; Blumer, Giblin, Lemermeyer, \& Kwan, 2016; Schulmeister, 2016; Wilson, 2016; Zhu, Gao, \& Li, 2016).

Nurses are on the front lines of patient care and are well positioned to help lead the technological revolution in clinical practice, education, and research. Providing care using technology requires new competencies in communication, assessment, data analysis, and data security measures. Nurses will have a pivotal role in the development, use, and impact of technology on patient care. Nurse educators must be prepared to teach new skills which, in turn, must be addressed by regulators responsible for ensuring patient safety in the digital health era.

\section{For-Profit Education}

Reporting on 2015 NSNA data $(n=4,284)$, Feeg \& Mancino (2016) found that $74 \%$ of nursing students have student loans or financial aid, up $4 \%$ from the previous year. Preliminary 2016 data reported by NSNA $(n=3,878)$ revealed a slight decrease in the percentage (72\%) of nursing students with loans (NSNA, 2016). BSN students have more debt than ADN students do, which is understandable because their programs are longer. According to 2016 preliminary NSNA data, $42 \%$ of the students have loans of $\$ 10,000$ to $\$ 50,000$, and $15 \%$ have loans of more than $\$ 50,000$ (NSNA, 2016). Of the nursing students with loans of more than $\$ 50,000,12 \%$ are in public colleges and universities; $35 \%$ are in private, not-for-profit colleges and universities; and $44 \%$ are in private, for-profit programs (Feeg \& Mancino, 2016).

For the past 6 years, the Obama administration has taken action regarding practices by some for-profit colleges where students accrue massive debt but are unable to repay because they are not employable. Under the gainful employment regulations published in 2014 and disclosure requirements that take effect in January 2017, graduates must not pay more than $8 \%$ of their total earnings or 20\% of their discretionary income annually toward debt repayment. Programs that exceed these levels risk losing their ability to participate in taxpayer-funded student loan programs. The U.S. Department of Education (DOE) estimates that approximately 1,400 programs 
serving 840,000 students would not meet these criteria and that $99 \%$ of the programs that would not pass the accountability standards are for-profit programs. Programs not meeting the criteria can make immediate changes to avoid sanctions. However, if significant changes are not made, the programs could lose their ability to provide federal student loans, which account for nearly $90 \%$ of for-profit programs' income (U.S. DOE, 2015).

In early September 2016, ITT Educational Services and ITT Technical Institute, a for-profit higher education institution, unexpectedly closed and declared bankruptcy. The closure affected 136 ITT locations across the country, including many nursing programs. The U.S. DOE estimates that 35,000 students were affected, including 3,000 nursing students in 42 nursing programs in 19 states. The DOE has offered assistance to ITT students, including loan discharges and assistance with credit transfers to other institutions. NCSBN and the BONs have assisted by disseminating information about successful models that states can use to help students to transition into other nursing programs.

At the same time that ITT closed, Career Point, another proprietary nursing program, abruptly closed. This program served approximately 1,500 LPN/VN and RN students in Texas and Oklahoma.

On September 22, 2016, the Accrediting Council for Independent Colleges and Schools (ACICS) lost U.S. DOE recognition. Without this recognition, ACICS cannot be a gatekeeper of federal aid. ACICS accredits for-profit and technical schools, including many proprietary nursing programs. ACICS has appealed the decision. This loss of recognition may affect BONs that require accreditation of nursing programs.

\section{Nursing Education Accreditation}

Even though most BONs have the authority to approve prelicensure programs, nearly all BSN and diploma programs and approximately half of the ADN programs are accredited by national nursing accreditors, the Commission on Collegiate Nursing Education or the Accrediting Commission for Education in Nursing. In 2016, another national nursing accrediting body, the Commission for Nursing Education Accreditation, or CNEA, began the process to accredit nursing programs. Several steps must be completed before the U.S. DOE can fully recognize CNEA as an accreditor.

In April 2016, the National Academies released a report, "Exploring the Role of Accreditation in Enhancing Quality and Innovation in Health Professions Education" (Cuff \& Perez, 2016). Key messages of this report include the following:

- Accreditation alone cannot determine professional standards.

- The interests of government and regulators are broader than those of individual professions and therefore present challenges for accreditation.

- Each profession's dialogue addressing innovation within accreditation will vary.

- The trend in accreditation is moving from a focus on structure and content to a focus on process and outcomes.

What are the best practices for measuring program outcomes? In 2016, a National Academies of Sciences, Engineering, and Medicine workshop report, "Quality in the Undergraduate Experience: What is it? How is it measured? Who decides?" provided insight into the importance of measuring quality in higher education, the difficulties in doing, so and some suggested actions (Matchett, Dalhberg, \& Rudin, 2016). Although not specifically addressing nursing, the report suggests actions for improving quality in higher education, including improving data gathering and sharing among educators, publishing best practices and guidelines, collaborating with international colleagues, and learning from other industries. Matsudaira (2016) surveyed the workshop participants and found that educators are measuring inputs (such as faculty-student ratios, expenditures, test scores, or program completion) when they should be measuring student or broader societal outcomes. At the National Academies accreditation workshop, David Benton, chief executive officer of NCSBN, stressed the importance of capturing data once and using it many times. For example, if BONs and the national nursing accreditors would share the data collected for approval and accreditation processes, nursing programs, accreditors, and BONs would all benefit.

\section{Health Care Delivery}

Making the health care delivery system safer and more efficient for the future is a global aim as the responsibilities for health care providers and the expectations and standards for delivery systems become increasingly congruent from nation to nation.

\section{Access and Quality of Care}

Annually, the environmental scan includes a summary of the National Healthcare Quality and Disparities Report from the Agency for Healthcare Research and Quality. This report provides an overview of the health of the U.S. population; access to care; the status of health care quality; and the disparities in care experienced by socioeconomic, racial, and ethnic groups. The most recent report (2015) revealed the following:

- Access to care in the United States is improving. 
- Quality of care, including patient safety, effective treatment, healthy living, and person-centered care, is progressing. Hospitalacquired conditions (pressure ulcers, falls, and infections) and adverse drug reactions significantly declined. Improvements have also been sustained in preventing urinary catheter infections and central-line bloodstream infections (Agency for Healthcare Research and Quality, 2015).

- Socioeconomic and racial disparities in health care, especially in access to health care, still exist, although improvement has occurred.

A 2016 report by the Centers for Medicare and Medicaid Services (CMS) on improvements in the quality of care in hospitals shows that avoidable hospital readmission rates have decreased since 2010. In 2015, Medicare beneficiaries avoided an estimated 100,000 unnecessary return trips to the hospital (Conway \& Groniger, 2016). Although readmissions are not a quality measure, avoidable readmissions may reflect ineffective care processes and can be used as a target for reducing length-of-stay or reimbursement goals. A study in Health Leaders Media illustrated an increase in readmissions tied to a decrease in overall mortality, suggesting that some readmissions are necessary and improve outcomes overall (Commins, 2016).

The Josiah Macy, Jr. Foundation (2016) suggests that RNs are the answer to access and quality of care issues in the United States. Given the proper preparation and the removal of barriers to their full scope of practice, RNs can help provide primary care services, even for those in severe health professional shortage areas. At their 2016 conference, the foundation recommended numerous ways in which RNs could effectively bolster primary care, including managing chronic diseases, following patients through health care transitions, and increasing patients' engagement in their own health care. These interventions would improve outcomes across several quality measures.

The full impact of this proposal requires several changes, including the following:

- Removal of state-level policy barriers that prevent RNs from practicing to the full extent of their training (considering the difficulty APRNs have practicing to the full extent of their training in many states, this challenge may be formidable)

- Continued movement away from fee-for-service and toward outcome-based payment to encourage RNs' inclusion on primary care teams

- Assignment of nurses to less traditional triage work and more care coordination

- A shift in educational preparation that balances the current focus on acute care with more content on primary care (Josiah Macy, Jr. Foundation, 2016).

The California Healthcare Foundation is also calling for RNs to help fill primary care disparities. Recommended tactics include using standardized procedures to empower RNs to make clinical decisions, reducing the triage burden on RNs, including RNs on care teams, implementing RN-led new patient visits, scheduling RNs to perform different roles on different days, and giving medication aids and LPNs/licensed vocational nurses expanded training and new responsibilities (Bodenheimer, Bauer, Olayiwola, \& Syer, 2015).

To address access-to-care issues in California, the legislature passed a bill allowing pharmacies to dispense hormonal contraceptives without a prescription. The intent is to improve access to and use of contraceptives. Oregon and Washington were the first states to allow this practice and several other states—Hawaii, New Mexico, Missouri, Tennessee, and South Carolina—have proposed legislation consistent with this practice (Karlamangla, 2016).

Since June 10, 2016, West Virginia pharmacies can dispense naloxone without a prescription to combat deaths from drug overdoses (Holdren, 2016). Similarly, CVS Health has expanded access to naloxone without a prescription in 31 states by use of a standing order with a physician (without an individual prescription) or a collaborative practice agreement (CVS Health, 2016). The 31 states include Arkansas, California, Colorado, Florida, Idaho, Indiana, Louisiana, Massachusetts, Minnesota, Mississippi, Montana, New Jersey, New York, North Dakota, Oregon, Pennsylvania, Rhode Island, Tennessee, Texas, Utah, Washington, Wisconsin, Connecticut, Kentucky, Maryland, North Carolina, New Hampshire, New Mexico, Ohio, Virginia, and Vermont. Additional states may introduce legislation in support of these practices in the coming year.

\section{Transition to Value-Based Care}

U.S. health care is experiencing a transformation from fee for service, which is volume driven, to pay for performance, which is driven by measured care strategies aimed at improved outcomes and patient engagement (CMS, 2016). This change is affecting health care delivery settings, particularly for APRNs. CMS drives much of the change through the Medicare program, the largest insurer in the United States, which accounts for $14 \%$ of the federal budget and $20 \%$ of all U.S. health care expenditure. Baby boomers are entering the Medicare roles at a rate of 10,000 per day. By 2020, approximately 50\% of what would have been traditional fee for service payments will have moved to alternative payment models (Deloitte Center for Health Solutions, 2016).

After seeking input from providers and patients, CMS rolled out the Medicare Access and CHIP Authorization Act of 2015 (MACRA) and the Merit Based Incentive System, which replace the outdated sustainable growth rate. Intended to provide support for small practices and to allow flexibility, the new structure gives providers a menu of quality measures from which to select and by which their outcomes will be measured (HHS, 2016b). No one model applies to all. The piloted Accountable Care Organizations are a model that can be pursued, although facilities and providers are welcome to design their own plans. Practices can choose to participate in shared savings for which they will be paid in a way similar to traditional fee-for-service models and receive a bonus at the end of the 
year if they have reduced spending below a certain target. Others can bundle payment for services for certain conditions and periods. If they spend less than they would have with unbundled payments, they may keep some of the savings.

In response to the new payment structure, most health systems are using consolidated models. They anticipate the various practice types they may need and the market elements (hospitals, ambulatory services, and community- and home-based care). Then, they purchase or contract with the various types of businesses to consolidate into a system containing all necessary elements (CMS, 2016). Which models will prevail is unknown.

In the fee-for-service era, insurance discounts and cost shifting obscure the actual costs. In the models of the future, accuracy of the cost of care is as important as understanding the measures of outcome improvements. In the future, health care dollars spent in preprocedural planning focused on the patient and his or her circumstances may be as important as those spent providing the procedure and postprocedure care. Moving patients' full, evolving story with them to each site of care and smoothly back to the primary care provider becomes the key. New models identify social determinants such as an environmental assessment, including caregivers and transportation, and follow the patient and the plan to procedure, postprocedure intensive care unit or general care, discharge in rehabilitation, long-term care, or home. A single-care coordinator pilots the patient along that trajectory.

Such targeted care preplans, if proving to deliver better coordination and team-driven improvements in outcomes, will undoubtedly ease the home-to-hospital-and-back-to-home process. Digital visits may be used in the preadmission and postdischarge phases, maximizing the communication with primary providers, team members, and even distant family members (Deloitte Center for Health Solutions, 2016). The emphasis for success is on the coordinating and planning functions that nurses at all levels share with their patients.

\section{Technology and Its Influence on Health Care Delivery}

Recent research agendas have urged harnessing the potential of innovative technologies for personalizing patient care, advancing clinical practice, and enhancing research capabilities. These new technologies have the potential to transform nursing and health care in general. Five of the most profound ways in which technology will shape the future of health care include telehealth, digital and continuous monitoring systems, robots and drones, artificial intelligence, and Ubercare.

\section{Telehealth}

Telehealth offers access in provider-shortage areas and innovative ways of monitoring care remotely. Between 2016 and 2020, annual increases in the global telehealth market are predicted to be $14.3 \%$, ultimately reaching $\$ 36.2$ billion—a substantial increase compared with $\$ 14.3$ billion in 2014 . Some factors influencing the telehealth movement include the following:

- Expansion of payment by government and private entities.

- Expansion of telehealth services beyond U.S. borders. As reported by the American Telehealth Association, more than 200 academic medical centers have agreements to provide telehealth services overseas.

- Increased momentum from the states. In 2015, more than 200 bills related to telemedicine were introduced in 42 state capitols. Twenty-nine states and the District of Columbia have laws requiring insurers to cover telehealth services.

- Growth of telehealth companies such as MDLIVE and Teledoc, expansion of employer health clinic services to include telehealth, and plans by retail clinics such as CVS and Walgreens to use telehealth.

- Accountable Care Organizations' use of telehealth technology to reduce cost and improve outcomes (Lacktman, 2015).

\section{Digital and Continuous Monitoring Systems}

Mobile phone applications and sensors worn on the body or clothing are revolutionizing the patient's role in health care and the ways patients and providers interact. Wearable technology and smart phone applications allow patients and providers to collect health assessment data, such as heart rate, blood pressure, insulin levels, oxygenation status, and gait abnormalities, more frequently and often more precisely than ever before (Wilson, 2016; Schulmeister, 2016; Shull \& Damian, 2015). Empowered by information from the Internet, patients want greater involvement in diagnosing and care planning (Hopia, Punna, Laitinen, \& Latvala, 2015; Park, Cho, \& Kim, 2016; Wilson, 2016; Schulmeister, 2016). Advanced clinical care, such as classifying arrhythmias, detecting seizure activity, and monitoring lung transplant patients, can be carried out virtually using body sensors and diagnostic capabilities that facilitate clinical decision making (Dabbset al., 2016; Park, Lee, \& Kang, 2015; Triantafyllopoulous, Korvesis, Mporas, \& Megalooikonomou, 2016; Wilson, 2016). Traditional nursing activities for stroke recovery, chronic disease management, postoperative rehabilitation, and monitoring of mobility and medication compliance in elderly patients can be Web based with wearable technologies (Rajanna et al., 2016; Shull \& Damian, 2015; Schulmeister, 2016).

\section{Robots and Drones}

Perhaps the most widely anticipated new technology in health care is an expanded use of robots. Tiny nanobots, nanites, nanomachines, and nanomites as well as large, comforting caretaker robots as seen in the movie BIG HERO 6 seem to be the promise of tomorrow's 
care (Hall \& Williams, 2014). The tiniest robotics may chase down and destroy cancer cells or help monitor internal responses to disease and medication (Nichol, 2016).

In addition, robots can be valuable in physical medicine, assisting with movement therapy through passive exercise, active-assisted exercise, and passive-assisted exercise. Even healthy patients with need, such as the elderly, may benefit from robots that provide mobility assistance and strength training and encourage range of motion. Robots can give direct assistance or noncontact coaching in facilities or at home. Moreover, robots may act as health care assistants, and they may serve a protective role for physicians and nurses when a patient has a highly contagious disease.

In Japan, some robot assistants have been used in long-term care facilities, and the enhancement of quality of life among the residents is notable (Howard, 2016). Some robots are purely for companionship and engagement (social robots). Others lead residents in wheelchair exercises, and still others act as the eyes and ears of relatives or staff members when they cannot be present (Leiber, 2016).

Google, Apple, and Amazon recognize that their home smart devices are being embraced in surprising ways. These voice-initiated devices are being adopted by older customers who find themselves bonding with them in some way. Some devices sit in the room and respond to questions or commands; some on moving platforms act like portable tablets. These devices already can monitor home temperature, door locks, and lightbulbs (Syrkett, 2016). We are a short distance from having a smart device or robot that engages more with people in a supportive way-perhaps one that educates, checks in, turns off the stove or other hazards, sends a status message to care providers or family, or performs other functions. Robotic drones also have the potential to revolutionize health care. At a cost of about $\$ 10,000$ for the small variety with the ability to carry about $5 \mathrm{lb}$, they can travel distances with some ease delivering supplies, blood products, or specimens (Mayo Clinic, 2016). Health care of the future will be, we hope, fully accessible, convenient, and home based.

\section{Artificial Intelligence}

Technology will achieve improved accuracy and timeliness of diagnoses as well. Computer-assisted diagnosis is already gaining a foothold in oncologic care, helping radiologists with breast cancer diagnoses and the identification and diagnoses of lung nodules (Cheng et al., 2016). Using pattern recognition and data analyses, these systems already enhance radiologic interpretations and surgical techniques (Huo, 2016). We will see a refinement in tools for assisting with diagnosis (Graber, 2016). Already, IBM's Watson computer is used to scan vast quantities of peer-reviewed medical publications, support cancer diagnoses, and recommend treatment plans ( $\mathrm{Ng}, 2016$; Susskind \& Susskind, 2015). IBM recently purchased cloud systems, imaging systems, population health systems, and analytics systems. The company is staking a \$4-billion investment on the expanding capabilities of Watson (Daher, 2016). One vision is that nurses, backed by the volumes of medical expertise in a system like Watson, can provide patients with accurate diagnoses and treatment plans (Susskind \& Susskind, 2015). The continual gains in knowledge of genomics will also help improve diagnosis and treatment, as will the increasing functionality and shared information of electronic medical records, with an emphasis on keeping the record available to patients and in their control (Beck, 2015).

\section{Ubercare}

The "Uberfication" of health care— the use of mobile and Internet technology to help patients receive care—seems to be the next quest for many entrepreneurs. On-demand health care companies, such as SkyMD and DermCheck, provide telemedicine services for dermatology. Vytaliz provides acute care services, offers flu shots, and performs laboratory tests. Heal, MedZed, and Pager focus on urgent care, and Pager combines with Uber for provider transportation to the patient's location (Rajan \& Wang, 2015; Henry, 2015; Linder \& Levine, 2016). Pager uses physicians, APRNs, nurses, and medical assistants—often in their spare time. Many physicians say they relish the opportunity for extra work (Henry, 2015). Since 2011, funds for on-demand health care have continually increased, totaling $\$ 692$ million (Rajan \& Wang, 2015). However, health-insurance plans typically do not cover these visits; therefore, out-of-network insurance claims, medical savings accounts, or the wallet are the funding source (Henry, 2015).

Some in the United States lack access to care because they are not able to transport themselves to health care facilities (Kumar, 2016). Other issues, including doctor deserts, create a lack of access. Some nonprofit organizations attempt to fill the gap by providing care sites and transporting patients to care or care to patients. Additionally, some state Medicaid programs provide nonemergency medical transportation, or NEMT, as a benefit (Kumar, 2016). Recently, the New York NEMT collaborated with Lyft to provide free rides on demand for its patients. Also, Uber collaborated with Passport Health to bring flu shots to communities. During one day in Boston; New York; Washington, DC; and Chicago, approximately 2,050 people were vaccinated (Kumar, 2016)

\section{Security of Health and Licensure Information}

Cybersecurity is an increasing concern for the health care industry. In 2015, hospitals and health care systems were the number one victims of cyberattacks. Hospitals are particularly vulnerable because of outdated technology, slowness to alter procedure in the face of an attack, and the open environment needed to facilitate good communication and quick response in times of crisis (Stokowski \& Mahajan, 2016). With hospital information systems growing more complex, patient records are vulnerable to hacking from many locations in 
the system. The best defense is to ensure that all staff members, including nurses, are educated about the potential threat (Lacey-Mabe, 2016). Most efforts to provide regulation and guidance for cybersecurity issues have been at the federal level. The recently created Health Care Industry Cybersecurity Task Force has been charged with reviewing challenges to secure networked medical devices, disseminating information to health care stakeholders to improve their preparedness for cybersecurity threats, and establishing a plan for the federal government to share actionable intelligence regarding cybersecurity threats to the health care industry (HHS, 2016c).

\section{Implications for Regulators}

The effects of technological innovation on nursing practice and education have many implications for nursing regulators. Along with considerations regarding the initial competencies and the content of education programs, regulators may also face new questions related to patient safety. For instance, if patients make more of their care decisions, including diagnosing themselves, managing their diseases, and providing their own assessment data, how do regulators assess the nurse's role in adverse outcomes? What is the responsibility of a nurse to judge the validity and quality of self-assessment data from a patient's mobile application? If the primary interaction between nurses and patients is virtual, patient safety may also develop a cyber dimension. Will regulation have to address the safety of patientgenerated data sent to providers or facilities by wearable devices? Security measures for transmitting and storing patient data from personal health devices are developing as fast as technology (Ali \& Khan, 2015; Park, Cho, \& Kim, 2016; Zhu, Gao, \& Li, 2016). How regulators will interface with the new data security systems is yet to be determined.

A notable chapter in the White House report, Preparing for the Future of Artificial Intelligence (Executive Office of the President, National Science and Technology Council Committee on Technology, 2016), addresses the issue of regulation and provides preliminary recommendations:

- Determine if artificial intelligence adds a risk to the health care service.

- Assess whether existing regulations are adequate or if further regulation is needed to protect the public.

- Remain cognizant of the regulator's role in public protection but be mindful of not creating unnecessary barriers that stifle advancement and growth.

- Collaborate with experts to derive the appropriate understanding and develop adequate regulatory responses to artificial intelligence.

BONs can make every effort to ensure that they are not creating unnecessary barriers to evolving technology and that they are encouraging nursing leadership in new areas. They can continue to collaborate with nursing organizations enforcing the ethical practice of nursing. And they can promote low-variation regulation across states through the interjurisdictional recognition of authorization to practice such as that provided in the nursing compacts.

\section{Health and Regulatory-Related Social Issues \\ Social Media}

In the first quarter of 2016, Facebook exceeded 1.65 billion monthly active users (Protalinski, 2016) and Twitter surpassed 310 million monthly active users (Statista, 2016a). As of June 2016, Instagram has grown to more than 400 million monthly active users (Statista, 2016b). The Pew Research Center (Perrin, 2015) reported that in from 2005 to 2015, the number of adults using social media jumped from $7 \%$ to $65 \%$ (See Figure 4 ).

\section{FIGURE 4}

\section{Social Network Use: 2005-2015}

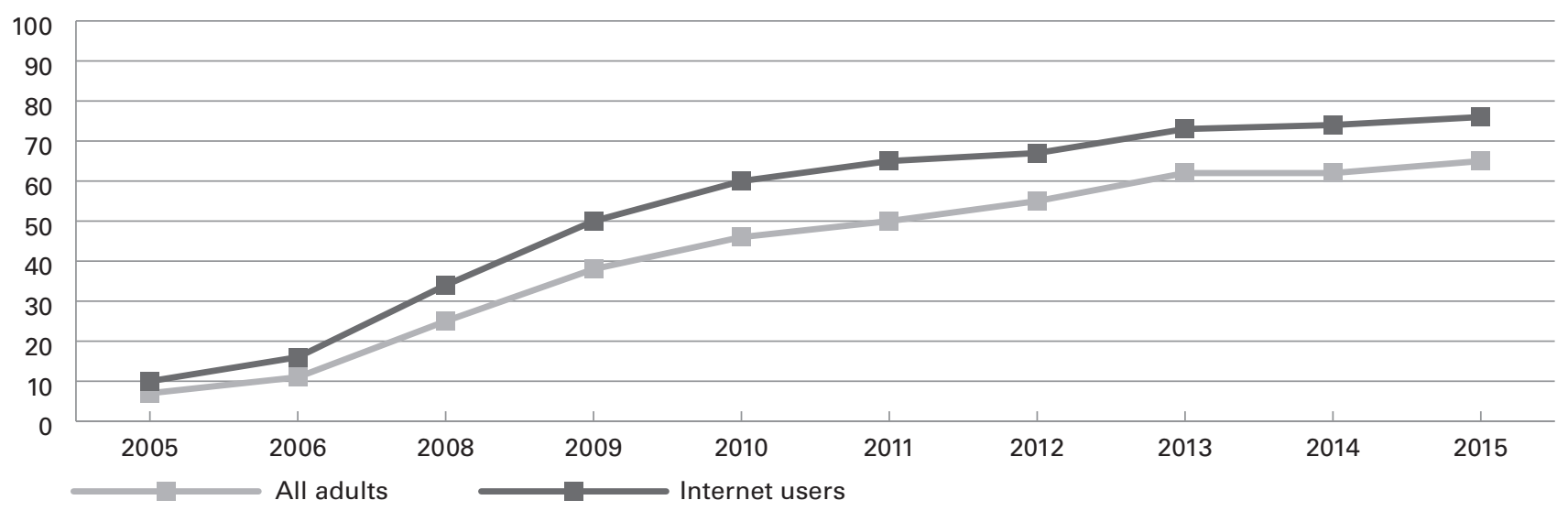


The Pew Research Center asserts that social media has affected much of our life, including our work, politics, political deliberation, global communication patterns, health information sharing, civic life, news consumption, communities, teenage life, parenting, dating, and stress levels, just to name a few. Virtually all hospitals have a social media presence now, according to Gandolf (2014). Social media violations are still a major concern in nursing and health care. After a series of ProPublica reports on social media abuses in nursing homes and assisted living facilities, on August 5, 2016, the CMS sent a memo to all state survey directors about their responsibility for protecting residents' confidentiality and privacy. CMS spelled out the federal regulations related to social media in four areas:

- Residents have a right to confidentiality and privacy, specifically the confidentiality and privacy of their medical records and their personal privacy. The CMS provided examples of social media violations, such as taking unauthorized pictures or recordings and keeping or distributing them through multimedia messages or on social media platforms.

- Residents have the right to freedom from verbal, sexual, physical, and mental abuse, as well as corporal punishment and involuntary seclusion, and the facility must develop written policies that prohibit mistreatment and abuse of residents. Regarding social media, mistreatment and abuse includes taking, keeping, or distributing humiliating or demeaning photographs or recordings despite whether a resident provides consent.

- The facility must provide annual training on abuse prevention to all staff members who provide care. Specifically, the facility must provide training on prohibiting staff members from taking, keeping, or distributing photographs or recordings that are humiliating or demeaning to the residents.

- The facility must ensure that all alleged violations are reported within the prescribed timeframe and are thoroughly investigated. For example, if a humiliating photograph of a resident is posted on social media, any staff member who sees it should immediately report it to the administration.

The CMS memo also specifies that the facility has the responsibility to report any violations to the state licensing boards or nurse aide registry for nurse aides. Although many guidelines exist regarding the responsible use of social media by nurses and other health care workers, social media is expected to remain a disciplinary issue for BONs.

\section{The Opioid Epidemic}

Although the United States has only 5\% of the world's population, 80\% of opioid consumption takes place here (Starner, 2016). Since 1999, prescriptions for opioids have increased $300 \%$, and some 1,000 emergency department visits per day are associated with misuse. In 2015 and 2016, the use of opioids, opioid addiction, and its related consequences became a major focus of the HHS, the U.S. Centers for Disease Control and Prevention (CDC), various states, and health care and practitioner groups.

Primary care providers account for approximately half of the opioid pain relievers dispensed (CDC, 2016). These providers report insufficient training in pain management and lack of evidence regarding how opioids improve various types of pain, as well as their effect on function and quality of life (CDC, 2016). HHS initiatives leading up to 2016 focused on this gap in education and training as well as emergency medication for overdose and medication-assisted treatment for addiction (HHS, 2015a; HHS, 2015b). Additionally, in 2015, the White House created an initiative that requires federally employed health care providers who prescribe opioid pain medications to complete opioid prescriber training (Community Anti-Drug Coalitions of America [CADCA], 2016). More than 40 provider groups made commitments to have more than 540,000 health care providers complete opioid prescriber training in the next 2 years. Joining the movement for increased education, the American Public Health Association called for action to reduce opioid abuse by releasing a policy statement that recommends the implementation of evidence-based provider training programs on mental health, substance abuse and overdose prevention, risks and benefits of high-dose opioid therapy, nonpharmacologic alternatives to pain management, and referral and treatment for patients suspected of drug abuse.

In 2016, federal agencies continued to announce initiatives to end the opioid epidemic. The U.S. Food and Drug Administration issued a plan to reassess its approach and focus on policies aimed at reversing the epidemic while providing patients with access to effective pain medication. More importantly, the CDC filled the gap in prescription recommendations by publishing guidelines on opioid prescribing for chronic pain (Dowell, Haegerich, \& Chou, 2016). These initiatives serve to educate practitioners to prevent further spread of opioid addiction in the United States.

For those addicted, the U.S. Surgeon General supports treating opioid abuse like a chronic disease. President Obama's Comprehensive Addiction and Recovery Act of 2016 (CARA, 2016) establishes a comprehensive, coordinated, balanced strategy through enhanced grant programs that expands prevention and education efforts while promoting treatment and recovery. The original proposed $\$ 1.1$ billion in funding is not reflected in the CARA legislation. Although CARA authorized over $\$ 181$ million each year in new funding to fight the opioid epidemic, monies must be appropriated every year through the regular appropriations process. Despite the funding concerns, CARA is the first major federal addiction legislation in 40 years and the most comprehensive effort undertaken (CADCA, 2016). CARA is a coordinated response to prevention, treatment, recovery, law enforcement, criminal justice reform, and overdose reversal (CADCA, 2016). It includes expanding opioid education to professionals, making naloxone even more available, and allowing medication-assisted 
therapy as well as mental health counseling for those addicted to opioids. CARA also expands the number of providers who can prescribe buprenorphine for addiction management to appropriately educated APRNs (CADCA, 2016).

\section{Nursing's Contribution to Ending the Opioid Epidemic}

Opioid addiction and substance use disorder (SUD) can affect anyone regardless of age, occupation, economic circumstances, ethnicity, or sex. They are progressive, chronic diseases, but they can be successfully managed and prevented. The multifaceted approach created through initiatives and law, which requires prescribers, regulatory authorities, pharmaceutical companies, employers, legislators, law enforcement, and the federal government, has a chance at turning the tide of SUD and opioid-related morbidity and mortality.

Nurses can make a critical contribution to ending the opioid epidemic. The American Nurses Association is committed to helping nurses fight opioid dependence, overdose, and pain by focusing on expanded access to medication-assisted treatment, prescriber education and training, abuse-deterrent drug formulations, the role of prescription drug monitoring programs, and increased access to opioid antagonists. The AACN announced commitments by more than 200 schools of nursing with APRN programs to educate APRN students on the CDC's guideline for prescribing opioids for chronic pain (Dowell et al., 2016).

NCSBN responded to the American Public Health Association call to action through an initiative to educate nurses and the public about substance use by removing the cost to NCSBN's two SUD-continuing education courses. Prevention starts with knowledge. Knowing the warning signs of SUD can lead to early detection and treatment.

Knowledge as well as advocacy at the legislative level and the bedside and office will reduce inappropriate prescribing. Just as nurses were leaders in the assessment of pain in the 1980s, nurses can be leaders in the movement to recognize that acute and chronic pain deserve different management modalities.

\section{Zika}

In 2016, a new infectious disease carried by a mosquito made headlines. Zika has raised concerns in the southern coastal United States; in Puerto Rico, however, economic factors affecting the country have compounded the problem to crisis levels. The tax credits that helped build the manufacturing base after the recession have expired, the manufacturing sector has dwindled, and the population is leaving, particularly physicians and nurses (Timirados, 2016; Respaut, 2016). As many as 700 physicians are expected to leave Puerto Rico this year, and many who remain do not accept Medicaid, which covers nearly half of the population. Nurses also appear to be leaving Puerto Rico for the mainland. In 2016, Florida alone received over 1,000 endorsements from Puerto Rico (personal communication, 2016). The U.S. government declared a health emergency in Puerto Rico in August when the number of people affected by Zika was approaching 11,000 (Fox News, 2016). Near the end of 2016, the first case of related microcephaly appeared ("1st Zika microcephaly baby born," 2016), at a time when pediatric specialists are in short supply. Moreover, the CDC has stated that Zika and other diseases spread by the same mosquito cannot be controlled with present methods (Zimmerman, 2016).

\section{Government and Legislative Issues}

\section{Elections}

The 2016 presidential election changed the landscape of the nation and the future of health care. An American businessman will sit in the White House, and he will chart a new path. Based on the campaign promises of Donald J. Trump, the new path will begin with a request that the Congress repeal the Affordable Care Act, the massive health care reform act enacted under President Obama (ACA) (Donald J Trump For President, 2016). A pre-election analysis of Trump's health care plan estimated that an ACA repeal would result in 19.7 million people losing coverage in 2018 (Saltzman \& Eibner, 2016). Perhaps recognizing that a repeal is not a one-stop solution to improving health care, the incoming president's plan includes a series of reforms that embrace free-market principles.

One of those reforms would encourage health insurance sales across state lines, an idea historically put forward by Republican presidential nominees (Khazan, 2016). Trump hopes this approach will increase competition, causing reduced insurance costs and increased consumer satisfaction (Donald J Trump For President, 2016). Other elements of Trump's plan include allowing individuals "to fully deduct health insurance premium payments from their tax returns," thus extending a benefit businesses currently enjoy (Donald J Trump For President, 2016). Trump's plan to "broaden healthcare access, make healthcare more affordable, and improve the quality of the care available to all Americans" also includes encouraging participation in health savings accounts, repealing and blocking grants for Medicaid and the Children's Health Insurance Program, and removing barriers for drug providers entering the market (Donald J Trump For President, 2016).

Health care policy was at the forefront of the national debate long before the ACA was enacted-and has certainly continued to be during the ACA's enactment and implementation and in numerous court cases and pieces of repeal legislation since. Little doubt exists that the new president will change the status quo. The unknown is how the changes will affect cost, access, and quality. 
On election night, the president-elect's party made gains across the country, including in state legislatures. Some historically blue chambers turned red, and some red states became darker shades of red. Control of state governments is especially crucial in the health care arena. Regulating facilities, professionals, and insurance systems; ensuring quality of care; and implementing major federal health policies are among some of the ways state governments shape the nation's health care landscape (Hess, Schwartz, Rosenthal, Snyder, \& Weil, 2008). The ACA had many facets that required state government action. For example, 32 states adopted Medicaid expansion under the ACA, and 19 did not (Kaiser Family Foundation, 2016). A changing political landscape could mean reversals of Medicaid expansion, especially with the fate of the ACA hanging in balance. Historically opposed to larger regulatory systems, the Republican Party looks to make government and the aspects of health care they control as small as possible. In contrast, the Democratic Party has historically preferred that government play a larger role in health care, championing universal health care and other health care policies that mandate coverage for all. Shifts in party control at all levels of state government will influence which bills are introduced, voted out of committee, passed through both chambers, and signed by the governor.

In 2016, Kentucky's House of Representatives fell to the Republicans for the first time since 1921 (Pierog, 2016). As a result, the Republican Party now controls all 30 chambers in the South (Greenblatt, 2016). Two other state chambers switched party control. In New Mexico and Nevada, Democrats gained a majority of House members (Grimm \& Kudon, 2016). Only the Massachusetts House chamber will continue to hold a Democratic supermajority (Grimm \& Kudon, 2016). In the Illinois House, the Democrats lost their supermajority, which was an advantage for passing the Democratic speaker's agenda and overriding Republican Governor Bruce Rauner's vetoes (Grimm \& Kudon, 2016).

In the 2016 elections, more state Senates changed parties than state Houses. In Iowa, a previously Democratic Senate became Republican, and Democratic Senate Majority Leader Mike Gronstal was ousted (Greenblatt, 2016). As a result, the Republicans will control the Iowa legislature and governor's office for the first time since 1998 (Petroski \& Pfannenstiel, 2016). Party control of the Senate chambers in Minnesota and Nevada also changed. The former switch to Republican control, and the latter switched to Democratic control (Grimm \& Kudon, 2016). Despite an election trend favoring the Republican Party, the Democrats in the Massachusetts Senate, just as in the House, maintained a supermajority.

At the top of the state tickets, several incumbent governors were defeated, making way for a wave of new governorships across the nation. Until December 5th, a question mark loomed over North Carolina's governor's seat (Graham, 2016). In the nation's longestrunning governor's race, Democrat Ray Cooper successfully defeated incumbent Governor Pat McCrory (Graham, 2016). Before conceding the race, the McCrory campaign alleged voter fraud in more than 100 counties while Cooper, confident in his lead, remarked early on that "Voters chose a new governor; it's time for the McCrory campaign to accept it," (Robertson, 2016). The close contest was caused by fractions within voters in the state on voting rights, transgender rights, Medicaid and abortion (Blinder \& Wines, 2016). Although the race is over, still-seated McCrory is continuing the fight, signing a bill into law on December 16th that limits the powers of the state's executive branch. McCrory called the move "hardly extreme" and says it intends to fix the "broken election process" among other issues in the state (Blau, 2016). Opponents of the move by the legislature and McCrory feel differently, calling the legislation a power grab by the Republican-led legislature to attempt to strip the Democratic governor of powers even before he is sworn in on January 7th (Robillard, 2016).

Although most other gubernatorial races were decided on election night, the results were not without their own drama. Several governorships changed party hands. The Democrats maintained control of the governorship in Delaware and West Virginia, and the Republicans gained control in Missouri, New Hampshire, and Vermont (Grimm \& Kudon, 2016). Republicans maintained control of several governorships, including those in Indiana and North Dakota, and the Democrats did not gain any governorships (Grimm \& Kudon, 2016).

With new administrations and political party structures at state capitols, much is uncertain, but one thing is not: both parties will be set to either defend or reclaim their seats in the 2018 midterm elections. Monitoring the next legislative sessions will be crucial.

\section{Federal Legislation \\ Telehealth}

Telehealth continues to be a hot topic in health policy discussions both in the U.S. Congress and federal agencies. Bills in Congress that address reimbursement and telehealth licensure in Medicare, Tricare, and the Department of Veterans Affairs (VA) continue to be introduced and receive hearings as ways to modernize our health care system and to increase access to beneficiaries across the country.

In 2016, Congress considered three bills addressing telehealth:

- The Veterans e-Health and Telemedicine Support (VETS) Act (2015). This bill would allow private health professionals under contract with the VA to deliver telehealth services to patients across the country with only one license. The Senate VA Affairs Committee held hearings on this bill, but it did not advance. 
- The National Defense Authorization Act (NDAA) (2016). Section 705 of the Senate-passed NDAA bill includes a section to expand access to telehealth services in the military's Tricare health system. Of concern is a provision that would move the location of licensure away from the patient to the location of the provider.

- CONNECT for Health Act (2016). This bill makes several changes to current Medicare policy to expand and modify the use of telehealth and remote patient monitoring services. The bill also clarifies that despite waiving some geographic restrictions for delivering telehealth services in Medicare, providers are still "subject to State licensing requirements."

In 2017, many telehealth bills addressing reimbursement and state licensure exemptions in federal health programs will be introduced. Prospects for bills that address telehealth reimbursement in Medicare will depend on a favorable cost estimate from the Congressional Budget Office. Previously, receiving such an estimate has been a significant hurdle because of the Congressional Budget Office's belief that reimbursement for additional telehealth services will result in an uptick in the use of those services and thus increase Medicare spending.

\section{Veterans Affairs}

The problem of access to care for veterans has been widely covered in the media. The Department of Veterans Affairs is composed of 139 hospitals but claims a medical professional shortage of 41,000 (physicians, nurses, and assistants). The U.S. Government Accountability Office (GAO) reports that the U.S. Department of Veterans Affairs (VA) appointments have improved by 20\% since 2011, but its recent analysis of the newly enrolled veterans showed, "The 120 newly enrolled veterans in GAO's review who were seen by providers waited from 22 days to 71 days from their requests that VA contact them to schedule appointments" (U.S. Government Accountability Office, 2016). More than 500,000 veterans are wait listed to get an appointment for 30 days or longer (Andrews, 2016). Former Senator and veteran Robert Dole endorsed the VHA policy change that would allow APRNs to practice to the full extent of their education and training and expand access to veterans across the country (Dole, 2016). Nurse practitioners have full practice authority in 21 states and the District of Columbia. The APRN proposed policy change would extend full practice authority to all APRNs working in a VHA facility. On May 25, the VA released a proposed rule that would grant full practice authority to APRNs practicing in the VA. During the policy's open comment period in The Federal Register, the APRN full practice proposal garnered the most comments on any policy ever published by the VHA. After reviewing over 200,000 submitted comments, the VHA issued its final rule on December 14th (Office of Public and Intergovernmental Affairs, 2016). The final rule permits full practice authority for certified nurse practitioners, CNSs, and CNMs within the VHA system (Office of Public and Intergovernmental Affairs, 2016). Although the fourth APRN role, the CRNA, will not be granted full practice authority under the final rule, VHA Under Secretary for Health Shulkin stated the VHA is "requesting comments on whether there are access issues or other unconsidered circumstances" to justify granting CRNA's full practice authority in future rulemaking endeavors (Office of Public and Intergovernmental Affairs, 2016).

\section{Licensing Exemptions}

In 2016, Congress began taking an interest in occupational licensing. This interest is not related only to the Supreme Court's ruling in the FNorth Carolina State Board of Dental Examiners v. Federal Trade Commission (2014) case but also to recent increased scrutiny of states unnecessarily requiring certain occupations to be licensed, creating a barrier to employment.

The Alternatives to Licensing That Lower Obstacles to Work, or ALLOW, Act (2016) would authorize individuals in a licensed occupation on a military installation located on land owned by the federal government to engage in their occupations, such as nursing, with a license issued by any state as long as the license is in good standing and the licensee has no outstanding enforcement actions against him or her. The Act would also allow certain licensed professionals that live and work in the District of Columbia to use a license from a different jurisdiction when practicing in the District at the approval of the city's attorney general. The bill is intended to be a licensing reform model for states to reduce the number of regulated professions.

\section{CARA}

In 2016, Congress passed CARA and President Obama signed it into law. This law includes many provisions of interest to state regulatory boards. It creates a grant program to help states help veterans who received medical training in the military to meet state certification or licensure in civilian health professions, such as nursing. The law also grants APRNs and physician assistants the authority to prescribe buprenorphine after receiving appropriate training.

CARA also made changes to VA hiring procedures, requiring the VA to obtain the past 20 years of license and discipline history for all health care providers it plans to hire. Additionally, the VA must report detailed information on VA health provider license violations to state regulatory boards in each state where the provider is licensed, regardless of whether the state requests the information. Finally, following allegations of provider misconduct being overlooked by VA facilities when providers transfer from one facility to another, the VA was directed to produce a report reviewing "each health care provider of the Department who transfers to another medical facility of 
the Department, resigns, retires, or is terminated to determine whether there are any concerns, complaints, or allegations of violations relating to the medical practice of the health care provider; and (2) to take appropriate action with respect to any such concern, complaint, or allegation." That report must be completed and sent to the House and Senate Committees on Veterans' Affairs by January 18, 2017.

\section{Affordable Care Act}

The ACA is a combination of two bills passed by Congress and signed by President Obama in 2010. The law mandates that all U.S. residents have a health insurance plan, prohibits insurers from denying coverage based on a pre-existing condition, and expands the Medicaid program.

Since the ACA's implementation in 2010, the uninsured rate has declined from $16 \%$ to a historic low of $9.1 \%$ in 2015 . In that period, an estimated 20 million people have gained health insurance (Obama, 2016; Cohen, Martinez, \& Zammitti, 2016). A Commonwealth Fund survey showed that $45 \%$ of adults enrolled in a marketplace plan in 2016, and 62\% of adults newly covered by Medicaid were previously uninsured (Levey, 2016a; Collins, Gunja, Doty, \& Beutel, 2016).

Disproportionately low-income communities in states that expanded Medicaid eligibility had much larger reductions in the percentage of the uninsured than similar communities in states that did not expand Medicaid (Radley, McCarthy, \& Hayes, 2016). Nineteen states, primarily located in the South, have not expanded Medicaid under the ACA. This region, which contains more than one-third of the U.S. population, is experiencing particularly acute health care provider shortages, lagging public health outcomes, and a disproportionate number of rural hospital closures (VanVleet \& Paradise, 2015; Ellison, 2016). Evidence suggests that adoption of Medicaid expansion might play a part in reversing these trends.

Not surprisingly, many of the new enrollees came in to the system with pre-existing conditions, and they have higher rates of certain diseases such as hypertension, diabetes, and depression than those who enrolled before the ACA took effect and have made use of more medical services (Young, 2016; Blue Cross Blue Shield, 2016). People in the states that expanded Medicaid are more likely to have a doctor, a place to go for care, and chronic diseases managed (Sanger-Katz, 2016). Children cared for primarily on Medicaid and then followed into adulthood demonstrate decreased hospital and emergency department visits as adults compared with those without childhood coverage (Miller \& Wherry, 2014). After the expansion of Medicaid coverage to everyone below a certain income level, lowincome people in Arkansas and Kentucky (states that expanded Medicaid coverage) appear to be healthier than comparable low-income people in Texas (a state that did not expand Medicaid). In Texas, $\$ 100$ billion in federal funding for Medicaid expansion is left unclaimed, although estimates indicate a return of \$1.30 in new economic activity for every \$1 paid toward expansion (Mangan, 2015).

The increased care has led to increased costs. Medical costs associated with caring for the new individual market enrollees were on average 19\% higher than employer-based group members in 2014 and 22\% higher in 2015 (Blue Cross Blue Shield, 2016). These higher costs have led to a problem of "adverse selection" for insurers, in which a disproportionate share of the new enrollees prove to be expensive because of the existence of known pre-existing conditions and the discovery of unknown ailments. (Young, 2016). Because the laws enforcing the mandate that all U.S. individuals buy insurance are weak, many healthy people have opted out of the system, leading insurers to raise their rates to make up for losses (Reinhardt, 2016). Insurers are expected to raise insurance rates for individual plans by an average of $10 \%$ in 2017, although a wide variation is expected (Abelson \& Sanger-Katz, 2016). For example, Minnesota rates are expected to rise by 50\% to 67\% (Montgomery, 2016). Government subsidies are expected to mitigate the costs for many enrollees (Kessler, 2016).

The increased costs have also led the exit of some high-profile insurers from the individual marketplace (Cox \& Semanskee, 2016a). A preliminary analysis of the insurance exchanges suggests that enrollees are likely to have fewer options for coverage in 2017. Nevertheless, only $6 \%$ of enrollees receive coverage through the individual market (Bernstein, 2016). Individual marketplace enrollment (currently at 11 million) could rise to 16 million in the near future, which would stabilize the cost in premiums and ensure participation by insurers (Altman, 2016).

Some argue that the increasing premiums for ACA policies indicate a problem with the strategy, but an analysis by the Urban Institute demonstrates that even with some increases (an average of $25 \%$ of the plans nationwide), the unsubsidized, nongroup premiums available from the marketplaces are 10\% lower than the average employer plan premiums (Blumberg, Holahan, \& Wengle, 2016).

Although a partisan divide still exists, support for a full repeal of the law is beginning to wane as an increasing share of U.S. individuals acknowledge that access to insurance and medical care has increased (Kirzinger, Sugerman, Wu, \& Brodie, 2016; Jacobs \& Mettler, 2016; Newman, 2016). With the strong success of ACA implementation in Kentucky (Artiga, Tolbert, \& Rudowitz, 2016), the noticeable reduction in the costs of prescription drugs for ACA enrollees (Levey, 2016c), and the funding for treatment of opioidaddicted patients in Medicaid expansion states (Levey, 2016b), support for the ACA may continue to grow.

By 2020, Medicare is expected to have spent $\$ 1$ trillion less than it might have without the ACA (Schoen, 2016). The ACA is a first step towards the broader goals of promoting health and providing affordable health care to all U.S. individuals (Butler, 2016). But, the program must change because the health plans on the individual marketplace are still too expensive for many people (Pear, 2016). 


\section{Deferred Action for Childhood Arrivals}

In June 2012, President Obama introduced the Deferred Action for Childhood Arrivals (DACA) program (also called the Dream Act). This enforcement policy temporarily defers deportations for about 1.9 million eligible undocumented children and young adults and provides temporary Social Security numbers and 2-year work permits. More than 3 years into the program, nearly 700,000 undocumented children and young adults had obtained DACA status (Gonzales, 2016). Studies have found that DACA has improved education and work opportunities for undocumented youth. However, in some states, licenses are restricted to citizens and legal permanent residents, which means graduating nursing students cannot be licensed. In some states, DACA students are precluded from the required clinical experiences. The future should provide more clarity on this issue, but, in the meantime, educators should know the state requirements regarding DACA so they can provide DACA students with reliable information.

\section{Regulation}

Although public protection is the mission of regulators, many persons are concerned that regulation can inhibit beneficial innovations and that delays in access to innovations can create patient harm (Stewart, 2010).

How will educators and regulators ensure that practicing nurses and nursing students obtain evidence-based knowledge of important, emerging areas? How will they ensure evidence-based knowledge of emerging technologies and awareness of the attendant risks? What will nursing regulation look like in 2025 or 2030? BONs will want to continue ensuring the public's trust, perhaps by including more members of the public on boards and promoting transparency at all levels of regulatory work. As always, BONs will continue to base regulation on evidence, wherever possible (Loversidge, 2016).

\section{Discipline}

A review of 10 years (2003-2013) of discipline cases submitted by BONs to NCSBN's disciplinary database (Nursys) revealed that $10 \%$ of the disciplinary actions were related to criminal conviction. To further address criminal convictions in nursing, NCSBN initiated a criminal conviction case review of 4,260 nurses who had BON actions in 2012 and 2013. This review showed that the majority of the crimes reported to BONs were not patient related. BONs took consistent actions across states and issued more severe disciplinary actions, such as license revocation, for more egregious crimes and crimes that involving patients (Zhong, McCarthy, \& Alexander, 2016). This study provides evidence that BONs diligently address criminal convictions and take disciplinary actions to remove nurses who may cause harm to public health and safety.

Studies consistently show that male nurses are overrepresented among nurses disciplined by BONs for violations of the nurse practice act. A mixed methods study was conducted by NCSBN to investigate the reasons for this overrepresentation. An advisory panel was convened, and a determination was made to explore whether the overrepresentation was caused by gender bias at the level of reporting or the level of discipline. No evidence was found suggesting that the overrepresentation results from gender bias at either level (Smiley \& McCarthy, 2016).

\section{Future of CORE and Performance Measurement}

Since 1998, NCSBN's Commitment to Ongoing Regulatory Excellence (CORE) project has measured BONs' performance to help manage and improve long-term program outcomes in discipline, licensure, education, and practice. Throughout the years, the CORE project has evolved to allow more concise measurements, enabling BONs to make evidence-based decisions. Most recently, in FY2012, the CORE framework was redesigned, and a model was developed to logically map how discipline, licensure, education, and practice inputs, outputs, and outcomes are linked to ensure that the public receives safe, competent care from nurses. The logic model warrants only relevant data to be collected to measure performance. As regulation evolves, the CORE project evolves as well to provide appropriate performance measures that accurately measure BONs' performance.

The CORE framework is a powerful tool in helping BONs assess their performance; however, it faces the common barriers of performance measurement, including using only subjective data to make evidence-based decisions (Johnston, n.d.), using the same measures year after year (Wolcott, 2016) and not reporting performance measurements in a timely manner (Poister, Aristigueta, \& Hall, 2014). For instance, the framework uses subjective data when surveying stakeholders on their opinions about how well the BON protects the public. Although the framework was updated in 2012, it still uses measures identified in 1998. Lastly, BONs typically receive CORE performance measurement reports 1 year after all data have been collected, resulting in untimely information for BONs to use to make evidence-based decisions.

To overcome these barriers, the CORE framework is incorporating a portal, into which data from all relevant sources are fed. After data are fed into the portal, BONs can generate customized reports that include only information appropriate for their current needs in a timely manner. Additionally, data sources are being reviewed to identify objective data measures that are current and comparable across all BONs, such as Nursys licensure and discipline data. This approach will remove the BONs' burden of collecting data and 
ensuring that they are accurate across all BONs. Therefore, these objective measures can be used to show any differences among factors, such as BON structure and size.

The CORE project should always evolve to ensure that BONs have current, relevant, reliable, and timely performance measures for making evidence-based decisions. Ultimately, this evolution will ensure that BONs continuously improve their performance in protecting the public from unsafe nurses.

\section{Enhanced Nurse Licensure Compact}

The Nurse Licensure Compact (NLC), which has been in operation for more than 15 years, allows RNs and LPN/VNs to have one multistate license in their home state with the ability to practice in their home state and other NLC member states without an additional license. The NLC model enables ease of practice across state borders both in-person and electronically. This mobility is essential for nurses practicing in different states via telehealth and nurse educators teaching in different states via distance education.

By 2015, the NLC had 25 member states, but not all other states were willing to become members because of differing state licensure requirements. In 2015, NCSBN members met to develop ways to enhance the NLC to encourage all states to join while keeping the compact safe for patients. The result was the enhanced NLC (eNLC) - a new version of the compact with uniform licensure requirements including criminal background checks.

A similar compact, the Advanced Practice Registered Nurse Compact (APRN Compact) allows APRNs to have a multistate license with the ability to practice in their home state and other APRN Compact member states without obtaining any additional APRN state licenses.

To become a member of the eNLC, a state must pass the eNLC language in its state legislature. Both the eNLC and the APRN Compact were introduced in state legislatures in the 2016 legislative session. During 2016, 10 states enacted the eNLC, and two states enacted the APRN Compact. The states enacting the eNLC are Arizona, Florida, Idaho, Missouri, New Hampshire, Oklahoma, South Dakota, Tennessee, Virginia, and Wyoming. Florida, Oklahoma, and Wyoming are not current NLC states and will be new to the NLC. The states enacting the APRN Compact are Idaho and Wyoming.

Approximately 22 states plan to introduce the eNLC in state legislatures in 2017, including 16 current NLC states and 6 states that would be new to the NLC. Additionally, approximately five states are planning to move forward with APRN Compact legislation.

The eNLC goes into effect 6 months after 26 states enact the eNLC legislation or on December 31, 2018, whichever comes first. Because 10 states have already enacted the eNLC, it may become effective in late 2017 or early 2018. The APRN Compact will become effective when 10 states pass the APRN Compact legislation.

\section{FTC and Regulatory Oversight}

The 2016 legislative session was the first full session since the decision in North Carolina State Board of Dental Examiners v. Federal Trade Commission (2014) by the U.S. Supreme Court. Having only the court's decision, the opinions of several state attorneys general, and a guidance document by the FTC, state policymakers began to introduce various measures to address the court's decision. Through executive and legislative action, states addressed various facets, including active market participant board membership, active supervision processes, exposure to federal antitrust law, and the state action doctrine. The proposed processes varied in method and complexity from a proposed change in the law to exempt a regulatory board from the jurisdiction of federal antitrust laws to the creation of a governmental agency to supervise every regulatory board decision. Although several governors signed executive orders, many proposed legislative efforts did not make it to governors' desks.

\section{Executive Orders}

The governor, as the overseer of the executive branch, has control over appointments and many functions of regulatory boards. Governors in Alabama, Delaware, Massachusetts, and Oklahoma used the executive orders to respond to the Supreme Court's ruling.

In Alabama, Executive Order No. 7, signed in June 2015, creates the Alabama Office for Regulatory Oversight of Boards and Commissions. This office may veto or modify actions voluntarily brought to them by active market participant-controlled boards and commissions (Alabama Exec. Order No. 7, 2015).

In Delaware, Executive Order No. 60, signed in April 2016, states that a committee will recommend standards and best practices to ensure that the state is meeting its goals of encouraging public safety and ensuring that residents can enter professions and occupations without unnecessary regulatory or administrative burdens. The committee will have nine members and other persons the governor may appoint. These members include the heads of various executive departments, such as the Secretary of the Department of Health and Social Services, and appointees of the House and Senate leadership (Delaware Exec. Order No. 60, 2016).

In Massachusetts, Executive Order No. 567, signed in March 2016, requires the Director of Professional Licensure, who oversees 28 boards, and the Commissioner of Public Health, who oversees eight boards, to review specific board actions to determine whether they have an anticompetitive effect. If an action is anticompetitive, the director or commissioner will determine whether it furthers an 
important state goal. If not, the policy will be vetoed. The executive order covers actions related to scope of practice, licensure requirements, price regulations, advertising and soliciting restrictions, competitive bidding restrictions, market participation restrictions on nonlicensees, and territorial allocations. The Massachusetts BON is supervised by the Commissioner of Public Health (Massachusetts Exec. Order No. 567, 2016).

In Oklahoma, Executive Order No. 2015-33, signed in July 2015, requires active market participant-controlled boards and commissions to implement supervision procedures. The Oklahoma Attorney General is charged with reviewing, vetoing, and modifying board and commission licensure and prohibition actions and issuing a written opinion explaining the decisions. Only nonrulemaking actions proposed by the boards and commissions must be submitted to the attorney general. Failure by a board or commission to follow the attorney general's decision will result in misconduct and subject the board members to removal for cause (Oklahoma Exec. Order No. 2015-33, 2015).

\section{Legislation}

Many state legislatures introduced legislation in response to the Supreme Court's decision. Included was model language from the conservative American Legislative Exchange Council (ALEC), which adopted the model language, called the Occupational Board Reform Act, in February 2016 (American Legislative Exchange Council, 2016). The act requires a newly formed office to actively supervise regulatory boards. The Office of Supervision of Occupational Boards would require boards and commissions to use the "least restrictive regulation necessary to protect consumers from present, significant, and substantiated harms that threaten public health and safety." The act also includes a newly created position in the legislature to review legislation that seeks to enact or modify an occupational regulation. Unlike the Supreme Court's decision, the ALEC legislation extends this required supervisory role over the legislature, a body that enjoys immunity from federal antitrust claims through the state action doctrine. The ALEC language was introduced in its full or partial form in Iowa and Minnesota, although the bill was not passed by either legislature (Iowa HF 2426, 2016; Minn. SF 3311, 2016).

In Alabama, attempts were made to address the Supreme Court's decision in 2016. In addition to the executive order discussed previously, bills were introduced in the state legislature. Senate Bill 80 states that the Alabama Board of Medicine is immune from liability under Federal antitrust laws (Ala. SB80, 2016). Although this bill failed, it was a unique proposal aimed at shielding a state regulatory board from the Supreme Court decision. A more lengthy process to ensure that regulatory boards receive immunity was introduced in the Senate and successfully enacted. Senate Bill 80 requires the Legislative Reference Service to review proposed board and commission action to determine whether it would significantly reduce competition (Ala. SB80, 2016). If it would, the Joint Committee on Administrative Regulation Review would meet, review the rule, and issue a determination of whether it should be approved, disapproved, amended, or withdrawn (Ala. SB80, 2016). The committee's process may include holding a public hearing and soliciting comments. Included in the language is a requirement that the committee give board and commission actions priority on the committee agenda.

Three states proposed that regulatory boards achieve compliance through consolidation, an umbrella structure, or rearrangement of agencies. In Arizona, House Bill 2501, which was supported by the governor, was introduced. The bill brings several health licensing boards, including the BON, under the Arizona Department of Health (Ariz. HB2501, 2016). An amendment to the bill assigns a supervisory role to the director of the Department of Health to oversee anticompetitive board decisions. During the bill's hearing in the House Health Committee, the governor's office and the chief sponsor testified that the amendment, and not the underlying bill language, was drafted in direct response to the North Carolina decision (Arizona Capital Television, 2016). The bill made it through the House but was defeated in the Senate.

In Massachusetts, the governor brought House Bill 4188 to the legislature. The bill, which did not pass, intended to "bring the Commonwealth's oversight of state-sponsored professional licensing boards into compliance with a recent decision of the United States Supreme Court" (Mass. Bill H4188, 2016). To do this, the bill proposed bringing the Board of Medicine under the Department of Public Health, where regulatory boards including the BON are located. House Bill 4188 gives authority to the Commissioner of Public Health to approve, disapprove, rescind in part or full, any act, rule, regulation, or policy proposed or implemented by any board under the commissioner's supervision (Mass. Bill H4188, 2016). The bill authorized actions by the commissioner based on a determination that the proposed or implemented action may restrain competition or potential competition (Mass. Bill H4188, 2016).

Oklahoma's Senate Bill 1540, also unsuccessful in the 2016 session, creates the State Department of Health Professional Licensure (Okla. SB1540, 2016), which would become home to 17 health licensing boards. The Oklahoma BON would be one of the 17 boards (Okla. SB1540, 2016).

In the wake of the North Carolina decision, regulatory boards and lawmakers looked to their state attorneys general for clarity and an assessment of their exposure to antitrust liability. In Oklahoma, the governor signed an executive order assigning the attorney general's office to supervise the states' regulatory board (Oklahoma Exec. Order 2015-33, 2015). In Wyoming, Senate File 55 also placed active supervision duties with the attorney general (Wyo. SF 0055, 2016). Senate File 55 requires active market participant-boards to 
receive written opinions from supervisors before taking actions that deal with a professional's scope of practice or the issuance, revocation, denial, or suspension of a license (Wyo. SF 0055, 2016).

\section{Future of Regulatory Oversight}

Discussions are taking place at state and national levels to address the impact of the North Carolina decision. As most states begin their 2017 legislative session, legislation similar to those mentioned above as well as new iterations are expected to appear before state lawmakers. Both government actors and stakeholders are bracing for decisions in various court cases that may further help the federal and state governments, state administrative agencies and boards, and stakeholders understand the breadth of the North Carolina decision.

Since the decision, regulatory bodies and professional organizations have been curious about which actions would be brought against boards and commissions and how courts would interpret the Supreme Court's decision. Although the decision set a new precedent for antitrust actions against regulatory boards and commissions, Kourtney S. Rodgers v. State of Louisiana Board of Nursing explores different avenue of immunity. On November 8, 2016 in the 5th Circuit Court of Appeals, the Louisiana BON was awarded 11th Amendment immunity in a case brought by a citizen, Kourtney Rodgers (Kourtney S. Rodgers v. State of Louisiana Board of Nursing, 2016). The BON terminated the nursing program at Grambling State University under its accreditation duties, and Rodgers, a student at the time of the BON's action, sued the BON, claiming it placed a restraint on trade and commerce, a violation of the Sherman Act and Clayton Antitrust Act (Kourtney S. Rodgers v. State of Louisiana Board of Nursing, 2016).

In a case wrought with procedural mishaps by the plaintiff, the District Court sought to determine if the BON should be awarded sovereign immunity under the 11th amendment (Lyon \& Wade, 2016). Ultimately, the court used the six-factor immunity determination test and found that the BON is an "arm of the state" and is therefore immune from the case brought by Rodgers. "Given the broad authority to regulate the nursing profession and nursing education in Louisiana, and its close connection to regulating public welfare, the BON is an 'arm of the state”" (Kourtney S. Rodgers v. State of Louisiana Board of Nursing, 2015). The six factors weighed to reach the determination were whether state statutes and case law characterize the agency as an arm of the state, the funding source of the agency, its degree of local autonomy, whether the agency is focused on local or statewide issues, if the agency can be sued under its name, and whether the agency can hold and use property (Kourtney S. Rodgers v. State of Louisiana Board of Nursing, 2015). Noting that the BON need not meet all six factors and that each factor need not be given equal weight, the court applied the test and found that the factors weighed in favor of granting 11 th amendment immunity to the BON.

In the appeal before the 5th Circuit, Rodgers argued that the district court erred by not applying the immunity test outlined in North Carolina State Board of Dental Examiners v. Federal Trade Commission (2014), called the Parker immunity test (Kourtney S. Rodgers v. State of Louisiana Board of Nursing, 2016). Obtaining Parker immunity requires a court to determine first whether anticompetitive action was taken by an active market participant-controlled body, and if so, whether the state actively supervised the decision (North Carolina State Board of Dental Examiners v. Federal Trade Commission, 2014). The district court did not apply the North Carolina State Board of Dental Examiners case, and in the opinion of the 5th Circuit, it did not err in its decision. "Case law implicitly recognizes that sovereign immunity and Parker immunity are separate and independent sources of immunity from private federal antitrust claims," and the Supreme Court clarified that its decision was limited: "members of regulated occupations" who "participat[ed] in state government” could sometimes look beyond Parker immunity to sovereign immunity as a defense," (Kourtney S. Rodgers v. State of Louisiana Board of Nursing, 2016).

Those closely watching antitrust cases against regulatory bodies may feel some relief after the 5th circuit's opinion. Although sovereign immunity may not apply in every antitrust case against a regulatory body, attorneys for boards and commissions may find they have a new avenue to explore in building their defense against future antitrust actions.

\section{APRN Consensus Model}

The addition of Alaska as a fully aligned APRN Consensus state helped make 2016 a relatively strong year for the APRN maps gains. Alaska Senator and former BON member Cathy Giessel sponsored Senate Bill 53 (2016), which became law. Through the rules process, Washington added the CNS role. West Virginia House Bill 4334 (2016) removed the required collaboration with a physician after a period of 3 years and applied the APRN title to all four roles. Through HB 580 (2016), Virginia conferred the APRN title on the CRNA and the CNM roles and granted autonomy in practice and prescribing for the CRNA. Virginia SB 463 (2016) further clarified the requirement of consultation with a licensed physician and evidence of a practice agreement.

State-based economic analyses have been reported in Florida, Texas, Massachusetts, Pennsylvania, Ohio, and West Virginia and demonstrate that the states can benefit economically by removing barriers to APRN practice and expanding access to primary care. West Virginia, which has several counties and rural areas with an insufficient supply of physicians and an aging physician workforce, experienced an expansion of Medical and Medicaid services in 2015 and 2016, which resulted in enrollments exceeding projections (Couch, 2016). The West Virginia legislation HB 4334 is an example of legislators realizing that removing barriers is one option for addressing state health outcomes and economic challenges. Evidence indicates that physicians do not lose economically in such a solution, 
and citizens gain primary care access (Pittman \& Williams, 2012). APRN advocacy for 2017 needs to include compelling arguments on how that strategy ultimately benefits the state in addressing opioid abuse concerns, expanding access to care, providing teleservices, and including APRNs as one of many state-based solutions to improving health outcomes.

To promote effective delegation and subsequently improve patient safety, nurses, assistive personnel, nurse leaders, and employers must have a clear understanding of the delegation process. NCSBN (2016b) published National Guidelines for Nursing Delegation based on current research and published literature to facilitate and standardize the nursing delegation process for the safe delegation of nursing responsibilities. These guidelines provide clarification on the responsibilities associated with delegation. These guidelines include an emphasis on the specific responsibilities of the employer or nurse leader, licensed nurse, and delegatee within the delegation process; a graphic model to illustrate the harmonization of the employer or nurse leader, licensed nurse, and delegatee responsibilities within the delegation process; and an explanation of the differences between delegation and assignment.

\section{Global Health}

The World Health Organization (WHO) estimates that in 2013, there were approximately 43.5 million physicians, nurse and midwives, and other health workers globally and that this number will increase to 67.3 million by 2030 (WHO, 2016a). Of the estimated 32.3 million nurses and midwives in 2030, 20\% will be in the Americas, and 25\% will be in Europe. Less than 5\% of the world's nurses will be in Africa (WHO, 2016b).

The estimate of health workforce supply changes dramatically when WHO modelers consider needs-based supply, that is, the number of health care providers needed to meet world health targets and universal health coverage. Workforce modeling with needsbased estimates show not an increase of 23.8 million but a global deficit of 14.5 million health workers. Although the starkest needsbased supply deficits will be in Africa (6 million) and Southeast Asia ( 4.7 million), calculations for countries in the Organization for Economic Cooperation and Development suggest a potential shortfall against heath service requirements of approximately 4 million (2016). The potential global shortfall by 2030 is between 16 and 19 million health workers. Global demand is estimated to increase from 48.4 million in 2013 to 80 million in 2030 (WHO, 2014).

WHO cautions against using global aggregate projections in place of estimates that consider context-specific considerations, such as economic growth, demographic trends, market trends, health worker production, demand for health care services, and migration. Instead, the global supply and demand simulations should be interpreted as clear evidence that demand and supply will fall short of population needs. Thus, WHO states that maintaining the status quo will not address health workforce needs. Greater, tailored investments will be necessary to facilitate greater access to health care services and improved health outcomes (WHO, 2014).

The United Nations (2015) ambitious agenda, Transforming our World: The2030 Agenda for Sustainable Development, contains 17 sustainable development goals and 169 global targets to help shift the world onto a more sustainable and resilient path. Nursing leaders, educators, and researchers have roles to play in promoting and achieving this global vision (Thompson, 2016; Wilson et al., 2016). Achieving universal access to health services and accelerating progress towards sustainable development goals are driving forces behind another global agenda with major implications for nursing, The WHO Global Strategy on Human Resources for Healtb: Workforce 2030 (WHO, 2014). This global strategy calls for all countries to work together to assess and address global health workforce needs.

The Workforce 2030 agenda has clear, significant implications of for nursing regulators (Benton \& Shaffer, 2016). Achievement of the Workforce 2030 objectives will create opportunities to build a new paradigm of regulation that is proactive and dynamic in a complex, digital, and global environment. Regulatory research is needed to determine optimal scopes of practice that incorporate the growing use of technologies by different types and levels of health workers. Strategic and operational planning will need to incorporate assessments of the potential effects of regulation, not just on practitioners or health care environments, but across a wide array of sectors and stakeholders. In addition, regulators may need to develop legislative, policy, and political competencies that will facilitate systemwide risk assessments and appropriate approaches. Lastly, greater mobility of health workers will require continued commitment to high-quality, real-time regulatory and workforce data, secure primary source verification of professional credentials, and collaboration across jurisdictions locally and globally.

\section{Regulation 2030}

On October 2 and 3, 2016, NCSBN hosted Regulation 2030, a meeting that brought regulators and nurse leaders from across the United States and around the world to Chicago to envision the future of regulation. Eighty nursing leaders attended the meeting, representing eight countries, 17 states, the District of Columbia, and two U.S. territories. Attendees included nurse regulators, a state senator from Minnesota, and representatives of the AACN, FTC, Federation of State Boards of Physical Therapy, Federation of State Medical 
Boards, National League for Nursing, Organization for Associate Degree Nursing, American Nurses Association, National Federation of Licensed Practical Nurses, Office of Economic Cooperation Development.

David Benton, RGN, PhD, FFNF, FRCN, FAAN, the keynote speaker, presented information to set the scene for what nursing regulation would look like in the year 2030 and presented the context and methodology to be used in pursuing the journey. The methodology was chosen to help nurse regulators and key stakeholders think ahead and prepare for the future by building on the present and engaging in outside the box, audacious thinking about the challenges and opportunities ahead. The influences of globalization and digitalization as well as other factors will influence the work of nursing regulation. Other factors include internal and external influences, such as migration, an increasingly complex health care system, and increasing societal demands for delivering 21st century regulatory models. Dr. Benton described the bibliometric analysis he performed of peer-reviewed literature related to professional self-regulation and occupational licensure. Using this methodology, he identified 25 emergent trends that accompany seven categories of regulation: governance, purposes and processes, licensee and registrants, workforce, education, fitness for practice, and technology and information.

\section{The 25 Emerging Trends}

Stephanie Ferguson, $\mathrm{PhD}, \mathrm{RN}, \mathrm{FAAN}$, provided an overview of the concept-mapping process and encouraged the audience to dream the future. Participants were assigned to small groups, and groups were assigned emerging trends. Participants were given note paper and colored pens and instructed to write down words and phrases that described what would be required to bring the emerging trend to fruition including the requirements—systems, processes, or technologies needed to make the theme or its deliverables a reality—and the deliverables_ changes to the state of nursing that may result from the theme and be perceived as positive or negative.

Next steps include determining the requirements and deliverables identified across concept maps as essential to positive outcomes in the future of regulation. These elements may become part of regulation's plan. Three papers describing the trends, methodology, and outcomes will be published in a supplement to the Journal of Nursing Regulation in 2017.

\section{Conclusion}

The IOM's 2010 report, the Future of Nursing, contained eight recommendations for nursing to advance health and lead change in the future. The recommendations were to be met by 2020. In 2016, a report indicated that the state coalitions and those working toward the advancement of the recommendations were making progress and encouraged them to continue.

Not only should nursing leadership continue to strive for the Future of Nursing goals, it should also add to its agenda the implications of this environmental scan and the outcomes from Regulation 2030, to be reported later in 2017.

Important findings from this report include the following:

- Technology will force us to rethink what we do, who does it, and how we do it.

- Licensure models will need to accommodate a digital age but also a robotic age.

- New payment models such as value-added reimbursement will drive safety.

- Patient-centered care is becoming patient driven.

- Increased scrutiny of regulators will continue by oversight bodies; accurate accountability and performance measures will be of primary importance.

- Nursing education needs to determine how curricula can be expanded to include coursework in robotics, programming, and genomics.

- Consumers will have greater expectations for both the provider and the regulator.

- The workforce must be flexible and adapt to changes in the environment.

- We can no longer think of ourselves in isolation; the future regulation of nursing will be a global endeavor.

In 2011, President Obama summarized the role of the regulator in addressing the new emerging technologies of tomorrow. His words remain relevant: "Our regulatory systems must protect public health, welfare, safety, and our environment while promoting economic growth, innovation, competitiveness, and job creation... it must identify and use the best most innovative and least burdensome tools for achieving regulatory ends" (Executive Order No. 13563, 2011). 


\section{References}

1st Zika microcephaly baby born in Puerto Rico. (2016, October 31). WebMD News from Health Day. Retrieved from http://www.webmd. com/news/20161031/puerto-rico-zika-microcephaly

Abelson, R., \& Sanger-Katz, M. (2016, June 16). Obamacare premiums are rising, not a little. The New York Times. Retrieved from http:// www.nytimes.com/2016/06/16/upshot/yes-obamacare-premiumsare-going-up.html

Agency for Healthcare Research and Quality. (2015). 2015 National healthcare quality and disparities report and 5 th anniversary update on the national quality strategy (AHRQ Publication No. 16-0015). Retrieved from http://www.ahrq.gov/research/findings/nhqrdr/ nhqdr15/executive-summary.html

Alabama Exec. Order No. 7. (2015, June 23). Retrieved from http://governor.alabama.gov/newsroom/2015/06/executive-order-number-7-2/

Ala. SB80. Reg. Sess. 2016. (2016). Retrieved from https://legiscan.com/ AL/bill/SB80/2016

Alaska SB 53. 29th Reg. Sess. (2016).

Ali, A., \& Khan, F. A. (2015). Key agreement schemes in wireless body area networks: Taxonomy and state-of-the-Art. Journal of Medical Systems, 39(10), 1-14.

Alternatives to Licensing that Lower Obstacles to Work (ALLOW) Act, S. 3158, 114th Cong. (2016).

Altman, D. (2016, August 29). The ACA marketplace problems in context (and why they don't mean Obamacare is 'failing'). The Wall Street Journal. Retrieved from http://blogs.wsj.com/washwire/2016/08/29/the-aca-marketplace-problems-in-context-andwhy-they-dont-mean-obamacare-is-failing/

Altman, S. H., Butler, A. S., \& Shern, L. (Eds). (2016). Assessing progress on the Institute of Medicine report on the future of nursing. Washington, DC: The National Academies Press.

Academy of Medical-Surgical Nurses; American Association of Colleges of Nursing; American Association of Critical-Care Nurses; Critical Care American Association of Neuroscience Nurses; American Association of Nurse Anesthetists; American Association of Nurse Practitioners; . . Public Health Nursing Section, American Public Health Association. (2016, June 27). RE: CMS-5517-P - Medicare program; Merit-Based Incentive Payment System (MIPS) and Alternative Payment Model (APM) incentive under the physician fee schedule, and criteria for physician-focused payment models (81 Fed.Reg. 28162 May 9, 2016) [Letter to Andrew M. Slavitt]. Retrieved from http://www. aacn.nche.edu/government-affairs/aprn-advocacy/CMS-QPPProposed-Rule-APRN-Comment.pdf

American Association of Colleges of Nursing. (2016, November). Employment of new nurse graduates and employer preferences for baccalaureate-prepared nurses. Retrieved from http://www.aacn.nche.edu/leading_ initiatives_news/news/2016/employment16

American Association of Nurse Practitioners. (2016). American Association of Nurse Practitioners fact sheet. Retrieved from https://www.aanp.org/ all-about-nps/np-fact-sheet

American Legislative Exchange Council. (2016, February). Occupational board reform act. Retrieved from https://www.alec.org/model-policy/ occupational-board-reform-act/

American Midwifery Certification Board. (2015). 2015 annual report. Retrieved from http://www.amcbmidwife.org/docs/annualreports/2015-amcb-annual-report.pdf?sfvrsn $=2$

Andrews, S. (2016). Twenty-six percent of veterans wait more than 30 days for appointments. Retrieved from http://wfla.com/2016/01/07/twentysix-percent-of-veterans-wait-more-than-30-days-for-appointments/

Arizona Capital Television (Producer). (2016, March 16). Senate Health and Human Services Committee. [Video file]. Retrieved from http:// azleg.granicus.com/MediaPlayer.php? view_id=3\&clip_id=17357
Ariz. HB2501, 52d Legis. 2nd Reg. (2016). Retrieved from https:/ legiscan.com/AZ/text/HB2501/id/1297665

Artiga, S., Tolbert, J., \& Rudowitz, R. (2016, April). Implementation of the ACA in Kentucky: Lessons learned to date and the potential effects of future changes. Retrieved from The Kaiser Family Foundation website: http://files.kff.org/attachment/issue-brief-implementation-of-theaca-in-kentucky-lessons-learned-to-date-and-the-potential-effectsof-future-changes

Auerbach, D. I., Buerhaus, P. I., \& Staiger, D. O. (2015). Will the RN workforce weather the retirement of the baby boomers? Medical Care, 53, 850-856.

Baquapuri, H. I., Wajdan, A., Kutafina, E., Misgeld, B., \& Jonas, S. M. (2016). Low-cost wearable for fatigue and back-stress measurement in nursing. Studies in Health Technology and Informatics, 225, 372.

Barnes, H., Maier, C. B., Sarik, D., Germack, H., Aiken, L., \& McHugh, M. D. (2016, May 13). Effects of regulation and payment policies on nurse practitioners clinical practices. Medical Care Research and Review. Retrieved from http://metatoc.com/papers/65315-effects-ofregulation-and-payment-policies-on-nurse-practitioners-clinicalpractices

Beck, M. (2015, June 29). How to take charge of your medical record. The Wall Street Journal. Retrieved from http://www.wsj.com/articles/ SB12367224787933994021304581064031716335262

Benton, D. C., \& Shaffer, F. A. (2016). Human resources for health 2030 and the regulatory agenda. Journal of Nursing Management, 24(6), $705-707$.

Bernstein, J. (2016, October 11). The Affordable Care Act is covering people, holding down costs and not killing jobs. The Washington Post. Retrieved from https://www.washingtonpost.com/posteverything/wp/2016/10/11/the-affordable-care-act-is-covering-peopleholding-down-costs-and-not-killing-jobs/

Blau, M. (2016, December 20). Why did North Carolina's Governor strip himself of power? Retrieved from CNN: http://www.cnn. com/2016/12/20/politics/north-carolina-power-grab/

Blinder, A., \& Wines, M. (2016, November 18). North Carolina republicans battle to save governor, trailing by Whisker. The New York Times. Retrieved from http://www.nytimes.com/2016/11/19/us/ north-carolina-governor-election.html?_r=0

Blue Cross Blue Shield. (2016). Newly enrolled members in the individual bealth insurance market after health care reform: The experience from 2014 and 2015. Retrieved from http://www.bcbs.com/healthofamerica/ newly_enrolled_individuals_after_aca.pdf

Blumberg, L. J., Holahan, J., \& Wengle, E. (2016). Are nongroup marketplace premiums really high? Not in comparison with employer insurance. The Urban Institute. Retrieved from http://www.urban. org/research/publication/are-nongroup-marketplace-premiumsreally-high-not-comparison-employer-insurance

Blumer, L., Giblin, C., Lemermeyer, G., \& Kwan, J. A. (2016). Wisdom within: Unlocking the potential of big data for nursing regulators. International Nursing Review. doi:10.1111/inr.12315/enhanced/ exportCitation/doi/10.1111/inr.12315

Bodenheimer, T., Bauer, L., Olayiwola, J. N., \& Syer, S. (2015). RN role reimagined: How empowering registered nurses can improve primary care. Retrieved from the California Health Care Foundation website: http://www.chcf.org/publications/2015/08/rn-role-reimagined

Brandt, C. L., Boellaard, M. R., \& Zorn, C. R. (2015). The faculty voice: Teaching in accelerated second baccalaureate degree nursing programs. Journal of Nursing Education, 54(5), 241-247.

Bridges, V. (2016, November 16). Duke officials test, refine robot-nurse. The News $\mathcal{E}$ Observer. Retrieved from http://www.newsobserver.com/ news/local/community/durham-news/article114543668.html

Brull, S., \& Finlayson, S. (2016). Importance of gamification in increasing learning. Journal of Continuing Education in Nursing, 47(8), 372-375. 
Buerhaus, P., Auerbach, D., \& Staiger, D. (2016). Recent changes in the number of nurses graduating from undergraduate and graduate programs. Nursing Economic \$, 34(1), 46-48.

Buerhaus, P. I., Auerbach, D. I., \& Staiger, D. O. (2014). The rapid growth of graduates from associate, baccalaureate and graduate programs in nursing. Nursing Economic\$, 32(6), 290-295, 311-312.

Butler, S. M. (2016). The future of the Affordable Care Act: Reassessment and revision. Journal of the American Medical Association, 316(5), 495497.

Centers for Medicare and Medicaid Services. (2016). MACRA, delivery system reform, Medicare payment reform. Retrieved from https://www.cms. gov/Medicare/Quality-Initiatives-Patient-Assessment-Instruments/ Value-Based-Programs/MACRA-MIPS-and-APMs/MACRA-MIPSand-APMs.html

Centers for Disease Control and Prevention. (2016, March). Prescribing data. Retrieved from https://www.cdc.gov/drugoverdose/data/ prescribing.html

Cheng, J.-Z., Ni, D., Chou, Y.-H., Qin, J., Tiu, C.-M., Chang, Y.-C., . . Chen, C.-M. (2016). Computer-aided diagnosis with deep learning architecture: Applications to breast lesions in US images and pulmonary nodules in CT scans. Scientific Reports, (6), 244-254. Retrieved from https://www.ncbi.nlm.nih.gov/pmc/articles/ PMC4832199/

Cohen, R. A., Martinez, M. E., \& Zammitti, E. P. (2016). Health insurance coverage: Early release of estimates from the national health interview survey, January-March 2016. Retrieved from National Center for Health Statistics website: http://www.cdc.gov/nchs/data/nhis/earlyrelease/ insur201609.pdf

Collins, S. R., Gunja, M., Doty, M. M., \& Beutel, S. (2016). Americans' experiences with ACA marketplace and Medicaid coverage: Access to care and satisfaction. The Commonwealth Fund. Retrieved from http://www.commonwealthfund.org/publications/issue-briefs/2016/ may/aca-tracking-survey-access-to-care-and-satisfaction

Commins, J. (2016, September 19.) Hospital readmissions are not the enemy. Health Leaders Media. Retrieved from http://www. healthleadersmedia.com/quality/hospital-readmissions-are-notenemy

Community Anti-Drug Coalitions of America. (2016, June 21). Comprehensive addiction and recovery act. Retrieved from http://www.cadca. org/comprehensive-addiction-and-recovery-act-cara

Comprehensive Addiction and Recovery Act (CARA), S. 524, 114th Cong. (2016). Retrieved from https://www.congress.gov/bill/114thcongress/senate-bill/524/text

Conway, P., \& Groniger, T. (2016). New data: 49 states plus DC reduce avoidable hospital readmissions. Retrieved from https://blog.cms. gov/2016/09/13/new-data-49-states-plus-dc-reduce-avoidable-hospital-readmissions/

CONNECT for Health Act, S. 2484, 114th Cong. (2016).

Conway, P., \& Groniger, T. (2016). New data: 49 states plus DC reduce avoidable hospital readmissions [Web log post]. Retrieved from https://blog.cms.gov/2016/09/13/new-data-49-states-plus-dcreduce-avoidable-hospital-readmissions/

Cook, W. (2013). Five reasons you can't ignore gamification. Chief Learning Officer Magazine, 5(8). Retrieved from: http://www.clomedia. com/2013/05/08/five-reasons-you-cant-ignore-gamification/

Couch, G. (2016, June 11). Meeting primary health care provider needs in West Virginia. Retrieved from the LinkedIn website: www.linkedin.com/ pulse/meeting-primary-health-care-provider-needs-westvirginiageorge-couch $[\mathrm{Au}$ : This URL is no longer active. Please provide an updated URL.]
Cox, C., \& Semanskee, A. (2016a). Analysis of UnitedHealth Group's premiums and participation in ACA marketplaces. Retrieved from The Kaiser Family Foundation website: https://kaiserfamilyfoundation.files. wordpress.com/2016/04/8862-analysis-of-unitedhealth-group_spremiums-and-participation-in-aca-marketplaces1.pdf

Cuff, P. A., \& Perez, M. M. (2016). Exploring the role of accreditation in enhancing quality and innovation in health professions education: Proceedings of a workshop. Washington, DC: The National Academies Press.

CVS Health. (2016). CVS Health to increase access to FDA-approved nasal naloxone for patients without insurance through improved affordability of NARCAN nasal spray at CVS pharmacy locations [Press release]. Retrieved from https://cvshealth.com/newsroom/press-releases/cvshealth-increase-access-fda-approved-nasal-naloxone-patients-without

Daher, N. M. (2016, March 11). Deep learning and medical imaging, the not-so-near future. Retrieved from the Diagnostic Imaging website: http://www.diagnosticimaging.com/pacs-and-informatics/deeplearning-medical-imaging-not-so-near-future

Dabbs, A. D., Song, M. K., Myers, B. A., Li, R., Hawkins, R. P., Pilewski, J. M., . . Alrawashdeh, M. (2016). A randomized controlled trial of a mobile health intervention to promote self-management after lung transplantation. American Journal of Transplantation, 16(7), 2172-2180.

Delaware Exec. Order No. 60. (2016). Retrieved from https://governor. delaware.gov/orders/EO060.pdf

Deloitte Center for Health Solutions. (2016). Connected health, how digital technology is transforming health and social care. U.K.: Deloitte Connected Health.

Dole, S. R. (2016, August 11). A veteran's stance on proposed VA rule to reduce wait times. Retrieved from http://www.forbes.com/sites/ realspin/2016/08/11/a-veterans-stance-on-proposed-va-ruleto-reduce-wait-times/\#553ce7936405

Donald J Trump For President. (2016). Healthcare reform to make America great again. Retrieved from https:/www.donaldjtrump.com/ POSITIONS/HEALTHCARE-REFORM

Dowell, D., Haegerich, T. M., \& Chou, R. (2016.) CDC guideline for prescribing opioids for chronic pain — United States, 2016. MMWR Recomm Rep 65(No. RR-1):1-49. Retrieved from http:// dx.doi.org/10.15585/mmwr.rr6501e1

Ellison, A. (2016, February 11). The rural hospital closure crisis: 15 key findings and trends. Retrieved from http://www.beckershospitalreview. $\mathrm{com} /$ finance/the-rural-hospital-closure-crisis-15-key-findings-andtrends.html

Elsevier. (2016, July). Revenue cycle management in home health care. Retrieved from http://icd-10online.com/wp-content/ uploads/2016/08/EL-Home-Health-White-Paper-web.pdf

Executive Office of the President, National Science and Technology Council Committee on Technology. (2016, October). Preparing for the future of artificial intelligence. Retrieved from https://www. whitehouse.gov/sites/default/files/whitehouse_files/microsites/ostp/ NSTC/preparing_for_the_future_of_ai.pdf

Exec. Order No. 13563, 76 Fed. Reg. 3821 (January 21, 2011).

Feeg, V. \& Mancino, D. J. (2016). Trends upward and trends downward reflecting a changing job market for new nursing graduates. Dean's Notes, 37(4-5), 1-5.

Felten, E. (2016, May 3). Preparing for the future of artificial intelligence. Retrieved from https://www.whitehouse.gov/blog/2016/05/03/ preparing-future-artificial-intelligence

Fox News. (2016, October 27). Health care, patients left in limbo as more doctors flee Puerto Rico. Retrieved from: http://www.foxnews.com/ health/2016/10/27/patients-left-in-limbo-as-more-doctors-fleepuerto-rico.html 
Gandolf, S. (2014). Nearly all US hospitals use social media. Now what [Web log post]? Retrieved from http://www.healthcaresuccess.com/blog/ hospital-marketing/nearly-us-hospitals-use-social-media-now.html

Gonzales, R. G. (2016, February 1). DACA at year three: Challenges and opportunities in accessing higher eduation and employment. Retrieved from https://www.americanimmigrationcouncil.org/research/daca-yearthree-challenges-and-opportunities-accessing-higher-education-andemployment

Graber, M. (2016). SIDM tools. Retrieved from http://www.improvediagnosis.org/page/Checklist

Graham, D. A. (2016, December 5). The North Carolina governor's race is finally over. The Atlantic. Retrieved from https://www.theatlantic. com/politics/archive/2016/12/north-carolina-governor-pat-mccroryconcedes-to-roy-cooper/509603/

Greenblatt, A. (2016, November 9). Republicans add to their dominance of state legislatures. Retrieved from Governing the States and Localities: http://www.governing.com/topics/elections/gov-republicans-adddominance-state-legislatures.html

Grimm, C., \& Kudon, J. (2016, November 10). 2016 State Election Results. Retrieved from JDSupra Business Advisor: http://www.jdsupra.com/legalnews/2016-state-election-results-72238/

Hall, D., \& Williams, C. (Directors). (2014). Big Hero 6 [Motion picture]. Retrieved from http://movies.disney.com/big-hero-6/about

Henry, Z. (2015, August 11). Will doctors on-demand disrupt the health care industry? Wire. Retrieved from http://www.inc.com/zoe-henry/ pager-on-demand-health-care-startups.html

Hess, C., Schwartz, S., Rosenthal, J., Snyder, A., \& Weil, A. (2008, April). States' roles in shaping high performance health systems. Retrieved from The Commonwealth Fund: http://www.commonwealthfund. org/usr_doc/Hess_statesrolesshapinghighperfhltsys_1115. pdf? section $=4039$

Holdren, J. \& Smith, M. (2016, August 30). President Obama to host White House Frontiers Conference in Pittsburgh, PA. Retrieved from https:// www.whitehouse.gov/blog/2016/08/30/president-obama-hostwhite-house-frontiers-conference-pittsburgh-pa

Holdren, W. (2016, May 22). Overdose reversal drug to be available without a prescription next month. Register Herald. Retrieved from http://www.register-herald.com/news/overdose-reversal-drug-to-beavailable-without-a-prescription-next/article_51a43fd8-9293-501db8dc-b3ac5c72a86c.html.

Hooper, J. I., McEwen, M., \& Mancini, M. E. (2013). A regulatory challenge: Creating a metric for $\mathrm{RN}-\mathrm{BSN}$ programs. Journal of Nursing Regulation, 4(2), 34-38.

Hopia, H., Punna, M., Laitinen, T., \& Latvala, E. (2015). A patient as a self-manager of their personal data on health and disease with new technology-challenges for nursing education. Nurse Education Today, 35(12), e1-e3.

Howard, J. (2016, October 3). Can robot pets comfort us as well as the real thing? Robot revolution sweeps Japan. Retrieved from CNN: http:// www.cnn.com/2016/10/03/health/robot-pets-loneliness/

Huo, Z. (2016, June 7). Study: Comparison of computer aided diagnosis and quantitative image analyses. Retrieved from Carestream: http://www. carestream.com/blog/2016/06/07/differences-between-computeraided-diagnosis-and-quantitative-image-analysis/

Institute of Medicine (IOM) Committee on the Robert Wood Johnson Foundation Initiative on the Future of Nursing. (2011). The future of nursing: Leading change, advancing health. Washington, DC: National Academies Press.

Iowa HF 2426. Reg. Sess. 2015-2016. (2016). Retrieved from http:// openstates.org/ia/bills/2015-2016/HF2426/

Jacobs, L. R., \& Mettler, S. (2016). Liking health reform but turned off by toxic politics. Health Affairs, 35(5), 915-922.
Johnston, K. (n.d.). What are the advantages and disadvantages of metrics and business management? Retrieved from http://smallbusiness.chron.com/ advantages-disadvantages-metrics-business-management-25880. html

Josiah Macy, Jr. Foundation. (2016, June). Registered nurses: Partners in transforming primary care. Presented at the Macy Foundation conference on preparing nurses for enhanced roles in primary care, Atlanta, GA.

Kaiser Family Foundation. (2016, October 14). Status of State Action on the Medicaid Expansion Decision. Retrieved from the Kaiser Family Foundation website: http://kff.org/health-reform/state-indicator/stateactivity-around-expanding-medicaid-under-the-affordable-careact $/$ ?current Timeframe $=0$

Karlamangla, S. (2016, April 8). What you need to know about California's new birth control law. Los Angeles Times. Retrieved from http:// www.latimes.com/local/lanow/la-me-ln-birth-control-law20160408-story.html

Kessler, G. (2016, September 1). The White House claim that 'most' people on Obamacare pay $\$ 75$ or less. The Washington Post. Retrieved from https://www.washingtonpost.com/news/fact-checker/ $\mathrm{wp} / 2016 / 09 / 01 /$ the-white-house-claim-that-most-people-onobamacare-pay-75-or-less/

Khazan, O. (2016, September 23). Trump-care would leave millions uninsured while somehow costing more. The Atlantic. Retrieved from http://www.theatlantic.com/health/archive/2016/09/hillarycare-trumpcare-obamacare/501248/

Kirzinger, A., Sugerman, E., Wu, B., \& Brodie, M. (2016). Kaiser Health tracking poll: August 2016. . Retrieved from The Kaiser Family Foundation website: http://kff.org/global-health-policy/poll-finding/ kaiser-health-tracking-poll-august-2016/

Kourtney S. Rodgers v. State of Louisiana Board of Nursing, No. 3:15-cv02176 (2015) U.S. Dist. LEXIS 169338

Kourtney S. Rodgers v. State of Louisiana Board of Nursing, No. 16-30023 (5th Cir. 2016).

Kumar, M. (2016, April 24). Uberification of healthcare: A mutation towards consumer centric health. HIT Leaders $\mathcal{E}$ News. Retrieved from http://www.hitleadersandnews.com/uberification-of-healthcare-a-mutation-towards-consumer-centric-health/

Lacey-Mabe, C. (2016, July 8). More safeguards are needed as reliance on technology and electronic records increases. Advance Healthcare Network for Nurses. Retrieved from http://nursing.advanceweb.com/Features/Articles/Cybersecurity-in-Hospitals.aspx

Lacktman, N. (2015, November 16). Five telemedicine trends transforming bealth care in 2016. Retrieved from https://www.foley.com/five-telemedicine-trends-transforming-health-care-in-2016/

Leiber, N. (2016). Europe bets on robots to help care for seniors. Retrieved from http://www.bloomberg.com/news/articles/2016-03-17/europe-betson-robots-to-help-care-for-seniors

Lemermeyer, G., \& Sadesky, G. (2016). The gamification of jurisprudence: Innovation in registered nurse regulation. Journal of Nursing Regulation, 7(3), 4-10.

Levey, N. (2016a, May 25). Obamacare receives healthy responses. The Chicago Tribune. Retrieved from http://digitaledition.chicagotribune. com/tribune/article_popover.aspx? guid =c8704905-f25a-4d76935c-f60fce $4684 \mathrm{e} 3$

Levey, N. (2016b, June 11). Fight against ACA hinders addiction care. The Chicago Tribune. Retrieved from http://digitaledition.chicagotribune.com/tribune/article_popover.aspx? guid =2f5fc641-28aa-4ad09616-d6b5f5fc1e6e

Levey, N. (2016c, August 18). Obamacare patients paying less for drugs. The Los Angeles Times. Retrieved from http://www.latimes.com/ nation/la-fi-obamacare-drug-costs-20160817-snap-story.html 
Li, Y., Kennedy, K. A. \& Fang, D. (2016). Special survey on vacant faculty positions for academic year 2016-2017. Retrieved from: http://www. aacn.nche.edu/leading-initiatives/research-data/vacancy16.pdf

Linder, J.A., \& Levine, D.M. (2016). Health care communication technology and improved access, continuity, and relationships: The revolution will be Uberized. JAMA Internal Medicine, 176(5), 643-644.

Loversidge, J. M. (2016). An evidence-informed health policy model: Adapting evidence-based practice for nursing and regulation. Journal of Nursing Regulation, 7(2), 27-33.

Lyon, K. C., \& Wade, A. R. (2016). Is your state board of nursing an "arm of the state"? Journal of Nursing Regulation, 7(3), 48-51.

Mangan, D. (2015, May 29). Don't mess with Medicaid expansion? A lesson from Texas. Retrieved from http://www.cnbc.com/2015/05/29/texaspays-a-big-price-for-saying-no-to-medicaid-expansion.html

Massachusetts Exec. Order No. 567. (2016, March). Retrieved from http://www.mass.gov/governor/legislationexecorder/execorders/ executive-order-no-567.html

Mass. Bill H4188, 189th Legis. (2016). Retrieved from https://malegislature.gov/Bills/189/House/H4188

Masui, A. (2016, January 27). Development of care robots growing in aging Japan. The Japan Times. Retrieved from http://www.japantimes.co.jp/news/2016/01/27/national/social-issues/developmentcare-robots-growing-aging-japan/\#.V-A1ePkrJaQ

Matchett, K., Dahlberg, M. L., \& Rudlin, T. (2016). Quality in the undergraduate experience: What is it? How is it measured? Who decides? Washington, DC: The National Academies Press.

Matsudaira, J. (2016). Defining and measuring institutional quality in higher education. Retrieved from http://sites.nationalacademies.org/cs/ groups/pgasite/documents/webpage/pga_170937.pdf

Mayo Clinic. (2016, May 6). Medical drones poised to take off. Retrieved from http://www.mayoclinic.org/medical-professionals/clinicalupdates/trauma/medical-drones-poised-to-take-off

McEwen, M. (2015). Promoting differentiated competencies for RN-toBachelor of Science in nursing program graduates. Journal of Nursing Education, 54(11), 615-623.

Metcalfe, H., Jonas-Dwyer, D., Saunders, R., \& Dugmore, H. (2015). Using the technology: Introducing point of view video glasses into the simulated clinical learning environment. Computers Informatics Nursing, 33(10), 443-447.

Minn. SB 3311, 89th Legis. (2016). Retrieved from https://www.revisor. $\mathrm{mn}$.gov/bills/bill.php?b=Senate\&f=SF3311\&ssn=0\&y=2015

Montgomery, D. (2016, September 30). Emergency for Minnesota as huge insurance premium hikes confirmed. The Saint Paul Pioneer Press. Retrieved from http://www.twincities.com/2016/09/30/ minnesota-insurance-premium-hikes-confirmed/

National Association of Colleges and Employers. (2015, September). The class of 2015 executive survey report. Retrieved from www.naceweb.org/ uploadedfiles/.../2015-student-survey-executive-summary.pdf

National Center for Health Statistics. (2016, October 7). CDC bealth expenditures. Retrieved from the Centers for Disease Control and Prevention website: http://www.cdc.gov/nchs/fastats/health-expenditures.htm

National Science and Technology Council, Networking and Information Technology Research and Development Subcommittee. (2016, October). The national artificial intelligence research and development strategic plan. Retrieved from https://www.nitrd.gov/PUBS/national_ ai_rd_strategic_plan.pdf

National Student Nurses' Association. (2016). 2016 NSNA survey of new graduate nurse employment. Manuscript in preparation.

National Council of State Boards of Nursing. (2015). Member board profiles: Education. Retrieved from https://www.ncsbn.org/Education. pdf
National Council of State Boards of Nursing. (2016a). National Nursing Database: A profile of nursing licensure in the US. Retrieved from https://www.ncsbn.org/national-nursing-database.htm

National Council of State Boards of Nursing. (2016b). National Guidelines for Nursing Delegation. Journal of Nursing Regulation, 7(1), 5-14.

The National Defense Authorization Act (NDAA), S. 2943, 114th Cong. (2016).

Newland, J. (2016, January 16). The 28th Annual APRN Legislative Update: Beyond the 50 states. Nurse Practitioner. 41(1), 8

Newman, R. (2016, April 21). Obamacare is in better shape than you think. Retrieved from http://finance.yahoo.com/news/obamacare-unitedhealth-repeal-not-happening-150042506.html

$\mathrm{Ng}$, A. (2016, August 7). IBM's Watson gives proper diagnosis for Japanese leukemia patient after doctors were stumped for months. New York Daily News. Retrieved from http://www.nydailynews.com/ news/world/ibm-watson-proper-diagnosis-doctors-stumped-article-1.2741857

Nichol, P. B. (2016, March 23). How medical robots will change healthcare Retrieved from http:/www.cio.com/article/3043172/innovation/ how-medical-robots-will-change-healthcarerhealth-get-familiarwith-it.html

North Carolina State Board of Dental Examiners v. Federal Trade Commission, 134 S. Ct. 1491 (2014).

Obama, B. (2016). United States health care reform: Progress to date and next steps. Journal of the American Medical Association, 316(5), 525532.

Oermann, M. H., Lynn, M. R., \& Agger, C. A. (2016). Hiring intentions of directors of nursing programs related to DNP-and $\mathrm{PhD}$-prepared faculty and roles of faculty. Journal of Professional Nursing, 32(3), 173-179.

Oklahoma Exec. Order No. 2015-33. (2015, July 17). Retrieved from https://www.sos.ok.gov/documents/executive/993.pdf

Okla. SB1540. 55th Legis. (2016). Retrieved from https://legiscan.com/ OK/bill/SB1540/2016

Organization for Economic Co-operation and Development. (2016, September 20). UN commission: New investments in global health workforce will create jobs and drive economic growth. Retrieved from http://www. oecd.org/newsroom/un-commission-new-investments-in-globalhealth-workforce-will-create-jobs-and-drive-economic-growth.htm

Park, H. S., Cho, H., \& Kim, H. S. (2016). Development of a multiagent $\mathrm{m}$-health application based on various protocols for chronic disease self-management. Journal of Medical Systems, 40(1), 1-14.

Park, J., Lee, K., \& Kang, K. (2015). Pit-a-Pat: A smart electrocardiogram system for detecting arrhythmia. Telemedicine and e-Health, 21(10), 814-821.

Pear, R. (2016, October 3). Next President likely to shape health law fate. The New York Times. Retrieved from http://www.nytimes. com/2016/10/03/us/politics/obama-health-care-act.html

Perrin, A. (2015, October 8). Social media usage: 2005-2015. Retrieved from Pew Research Center website: http://www.pewinternet. org/2015/10/08/social-networking-usage-2005-2015/

Petroski, W., \& Pfannenstiel, B. (2016, November 9). GOP wins majorities in Iowa House, Senate; Gronstal defeated. The Des Moines Register. Retrieved from http://www.desmoinesregister.com/story/news/ politics/2016/11/09/gop-wins-majorities-iowa-house-senate-gronstal-defeated/93087764/

Phillips, S. (2017). The 29th annual APRN legislative update. The Nurse Practitioner, 42(1) 18-46.

Pierog, K. (2016, November 9). Republicans hold on to state legislative edge in U.S. election. Retrieved from Reuters: http://www.reuters.com/article/us-usa-election-legislatures-idUSKBN13424N 
Pittman, P., \& Williams, B. (2012). Physician wages in states with expanded APRN scope of practice. Nursing Research and Practice. dx.doi.org/10.1155/2012/671974

Presti, C. R. (2016). The flipped learning approach in nursing education: A literature review. Journal of Nursing Education, 55(5), 252-257.

Protalinski, E. (2016, April 27.) Facebook passes 1.65 billion monthly active users, 54\% access the service only on mobile. Retrieved from http://venturebeat.com/2016/04/27/facebook-passes-1-65-billion-monthlyactive-users-54-access-the-service-only-on-mobile/

Radley, D. C., McCarthy, D., \& Hayes, S. L. (2016). Rising to the challenge: The Commonwealth Fund scorecard on local health system performance. Retrieved from The Commonwealth Fund website: http://www. commonwealthfund.org/interactives/2016/jul/local-scorecard/

Rajan, R., Wang, T. (2015, November 23) Why there is no Uber for healthcare. Rock Health. Retrieved from https://rockhealth.com/whythere-is-no-uber-for-healthcare

Rajanna, V., Vo, P., Barth, J., Mjelde, M., Grey, T., Oduola, C., \& Hammond, T. (2016). KinoHaptics: An automated, wearable, Haptic assisted, physio-therapeutic system for post-surgery rehabilitation and self-care. Journal of Medical Systems, 40(3), 1-12.

Rechtoris, M. (2016, March 9). 7 statistics on urgent care centers, EDs $\mathcal{E}$ retail clinics. Retrieved from http://www.beckersasc.com/asc-qualityinfection-control $/ 5$-statistics-on-urgent-care-centers-emergencydepartments.html

Reinhardt, U. (2016). Why are private health insurers losing money on Obamacare? Journal of the American Medical Association, 316(13), $1347-1348$.

Respaut, R. (2016, October 11). Take a Number: Why people wait more than a year to see a doctor in Puerto Rico. Retrieved from Reuters: http:// www.reuters.com/investigates/special-report/usa-puertorico-healthcare/

Robertson, G. (2016, November 18). Democrat's lead widens in North Carolina governor's race. Retrieved from http://www.usnews.com/news/ politics/articles/2016-11-18/democrats-lead-widens-in-north-carolina-governors-race

Robillard, K. (2016, December 15). Cooper threatens to sue over North Carolina GOP 'power grab'. Retrieved from Politico: http://www.politico. com/story/2016/12/roy-cooper-republican-power-grab-north-carolina-232682

Saltzman, E., \& Eibner, C. (2016, September). Donald Trump's health care reform proposals: Anticipated effects on insurance coverage, out-of-pocket costs, and the federal deficit. Retrieved from The Commonwealth Fund website: http://www.commonwealthfund.org/ /media/files/publications/issue-brief/2016/sep/1903_saltzman_trump_hlt_care_reform_ proposals_ib_v2.pdf

Sanger-Katz, M. (2016, August 9). Affordable Care Act appears to have improved health. The New York Times. Retrieved from http://www. nytimes.com/2016/08/09/upshot/obamacare-appears-to-be-makingpeople-healthier.html

Schoen, C. (2016). The Affordable Care Act and the US economy: A five-year perspective. Retrieved from The Commonwealth Fund website: http:// www.commonwealthfund.org/publications/fund-reports/2016/feb/ aca-economy-five-year-perspective.

Schulmeister, L. (2016). Technology and the transformation of oncology care. Seminars in Oncology Nursing, 32(2), 99-109.

Shull, P. B., \& Damian, D. D. (2015). Haptic wearables as sensory replacement, sensory augmentation and trainer-a review. Journal of Neuroengineering and Rehabilitation, 12(1), 1.

Smiley, R. A., \& McCarthy, C. (2016). A mixed-methods study of gender differences in nurse reporting and nurse discipline. Journal of Nursing Regulation, 7(3), 33-40.
Starner, C. (2016, June 28). America's opioid epidemic: Part 1 - diagnosing the problem. Retrieved from https://www.primetherapeutics.com/en/ news/prime-insights/2016-insights/2016-06-28-opioid-1.html

Statista. (2016a). Number of monthly active Twitter users worldwide from 1 st quarter 2010 to 3rd quarter 2016 (in millions). Retrieved from https:// www.statista.com/statistics/282087/number-of-monthly-activetwitter-users/

Statista. (2016b). Number of monthly active Instagram users from January 2013 to June 2016 (in millions). Retrieved from https://www.statista. com/statistics/253577/number-of-monthly-active-instagram-users/

Stewart, L. A. (2010). The impact of regulation on innovation in the United States: A cross-industry literature review. Retrieved from http://www. itif.org/files/2011-impact-regulation-innovation.pdf

Stokowski, L. A., \& Mahajan, S. M. (2016, June 16). Nurses and cyber security: What you need to know. Medscape. Retrieved from http:// www.medscape.com/viewarticle/864669

Susskind, R., \& Susskind, D. (2015). The future of the professions: How technology will transform the work of human experts. Cary, NC: Oxford University Press, USA.

Syrkett, A. (2016, October 18). Google Home, Amazon Echo, Apple HomeKit: Everything you need to know. Curbed. Retrieved from http://www.curbed.com/2016/10/18/13290348/amazon-echogoogle-home-apple-homekit-home-tech

Poister, T. H., Aristigueta, M. P., \& Hall, J. L. (2014). Managing and measuring performance in public and nonprofit organizations: an integrated approach. Hoboken, NJ: John Wiley \& Sons.

Thompson, P. E. (2016). New generation leaders: the future for nursing and midwifery. Journal of Nursing Management, 24(3), 273-274.

Timirados, N. (2016, June 29). Puerto Rico's economic crisis in five charts. The Wall Street Journal. Retrieved from https://blogs.wsj.com/ ecomonics/2016/06/29/puerto-rics-economic-crisis-in-five-charts/

Triantafyllopoulos, D., Korvesis, P., Mporas, I., \& Megalooikonomou, V. (2016). Real-time management of multimodal streaming data for monitoring of epileptic patients. Journal of Medical Systems, 40(3), $1-11$.

United Nations. (2015). Resolution 70/1. Transforming our world: The 2030 agenda for sustainable development. Retrieved from http://www.un.org/ $\mathrm{ga} /$ search/view_doc.asp?symbol=A/RES/70/1\&Lang $=\mathrm{E}$

U.S. Bureau of Labor Statistics. (2016). Occupational employment statistics. Retrieved from http://www.bls.gov/oes/oes_emp.htm

U.S. Census Bureau (2016). Annual estimates of the resident population for the United States, regions, states, and Puerto Rico: July 1, 2015. Retrieved from http://www.census.gov/popest/data/index.html

U.S. Department of Education. (2015). Fact sheet: Obama administration increases accountability for low-performing for-profit institutions. Retrieved from http://www.ed.gov/news/press-releases/fact-sheet-obamaadministration-increases-accountability-low-performing-profitinstitutions

U.S. Department of Health and Human Services' Health Resources and Services Administration. (2010). The registered nurse population: Findings from the 2008 national sample survey of registered nurses. Retrieved from http://bhpr.hrsa.gov/healthworkforce/rnsurvey2008.html

U.S. Department of Health and Human Services. (2015a, March 26). HHS takes strong steps to address opioid-drug related overdose, death and dependence. Retrieved from http://www.hhs.gov/about/ news/2015/03/26/hhs-takes-strong-steps-to-address-opioid-drugrelated-overdose-death-and-dependence.html

U.S. Department of Health and Human Services. (2015b, July 25). HHS increases access to substance use disorder treatment. Retrieved from http:// www.hhs.gov/about/news/2015/07/25/hhs-increases-access-to-substance-use-disorder-treatment.html 
U.S. Department of Health and Human Services. (2016a, August 12). E-health and telemedicine. Washington, D.C.: Author. Retrieved from https://aspe.hhs.gov/sites/default/files/pdf/206751/TelemedicineEHealthReport.pdf

U.S. Department of Health and Humans Services. (2016b, October 14). HHS finalizes streamlined Medicare payment system that rewards clinicians for quality patient care. Retrieved from https://www.hhs.gov/about/ news/2016/10/14/hhs-finalizes-streamlined-medicare-paymentsystem-rewards-clinicians-quality-patient-care.html

U.S. Department of Health and Human Services. (2016c). Health care industry cybersecurity task force. Retrieved from http://www.phe.gov/ preparedness/planning/CyberTF/Pages/default.aspx

U.S. Government Accountability Office. (2016). Actions needed to improve newly enrolled veterans' access to primary care (Publication No. GAO-16328). Washington, DC: Author. Retrieved from http://www.gao. gov/products/GAO-16-328

VanVleet, A., \& Paradise, A. V. (2015, January 20). Tapping nurse practitioners to meet rising demand for primary care. Retrieved from the Kaiser Family Foundation website: http://kff.org/medicaid/issue-brief/tapping-nurse-practitioners-to-meet-rising-demand-for-primary-care/

Veterans E-Health and Telemedicine Support Act of 2015, S. 2170, 114th Cong. (2015).

Va. HB 580. Reg. Sess. 2016-2017. (2016).

Va. SB 463. Reg. Sess. 2016-2017. (2016).

Miller, S., \& Wherry, L. (2014, July 5). The long-term health effects of early life Medicaid coverage. Retrieved from http://www-personal.umich. edu/ mille/MillerWherry_Prenatal2014.pdf

W. Va. HB 4334. 82nd Reg. Sess. (2016).

Wilson, D. (2016, July 25). An overview of the application of wearable technology to nursing practice. Nursing Forum. Retrieved from https://www.ncbi.nlm.nih.gov/pubmed/27455029

Wilson, L., Mendes, I. A. C., Klopper, H., Catrambone, C., Al-Maaitah, R., Norton, M. E., \& Hill, M. (2016). 'Global health' and 'global nursing': Proposed definitions from The Global Advisory Panel on the Future of Nursing. Journal of Advanced Nursing, 72(7), 15291540 .

Wolcott, R. C. (2016, September 23). Don't Be Tyrannized by Old Metrics. Harvard Business Review. Retrieved from https://hbr. org/2016/09/dont-be-tyrannized-by-old-metrics

Wood, F. G. (2016). Where are the faculty? Fulfilling the traditional faculty role at a distance. Journal of Professional Nursing, 32(4), 256261.

World Health Organization. (2014). Health workforce 2030: A global strategy on buman resources for health. Retrieved from http://www.who.int/ workforcealliance/knowledge/resources/strategy_brochure2014/en/

World Health Organization. (2016a) High level commission on health employment and economic growth. Retrieved from http://www.who.int/hrh/ com-heeg/hrh_heeg_call/en/

World Health Organization. (2016b). The global strategic directions for strengthening nursing and midwifery. Retrieved from http://www.who. int/hrh/nursing_midwifery/global-strategy-midwifery-2016-2020/ en/

Wyo. SF 0055. 63d Legis. (2016). Retrieved from http://legisweb.state. wy.us/2016/Introduced/ SF0055.pdf

Xue, Y., Ye, Z., Brewer, C., \& Spetz, J. (2016). Impact of state nurse practitioner scope-of-practice regulation on health care delivery: Systematic review. Nursing outlook, 64(1), 71-85.

Yedidia, M. J. (2016). Evidence for improving preparation, recruitment, and retention of nurse faculty: Findings from EIN-funded studies. Journal of Professional Nursing, 32(3), A1-A6.
Young, J. (2016, March 30). Obamacare enrollees are sick and they're getting a lot of health care. The Huffington Post. Retrieved from http://www.huffingtonpost.com/entry/obamacare-enrollees-aresick_us_56face7be4b0143a9b497571

Young, L. K., Adams, J. L., Lundeen, S., May, K. A., Smith, R. \& Wendt, E. (2016). Nurses for Wisconsin: A collaborative initiative to enhance the nurse educator workforce. Journal of Professional Nursing, 32(4), 292-299.

Zhong, E. Z., McCarthy, C., \& Alexander, M. (2016). A review of criminal convictions among nurses 2012-2013. Journal of Nursing Regulation, 7(1), 27-33.

Zhu, H., Gao, L., \& Li, H. (2016). Secure and privacy-preserving body sensor data collection and query scheme. Sensors, 16(2), 179.

Zimmerman, B. (2016, October 27). Zika likely here to stay, says CDC director. Becker's Hospital Review, Infection Control and Clinical Quality. Retrieved from http://www.beckershospitalreview.com/quality/zikalikely-here-to-stay-says-cdc-director.html 


\section{APPENDIX A}

\section{Changes to State Policies}

A review of the position and practice statements, clinical practice advisories, advisory and declaratory rulings, advisory opinions, and interpretive guidelines revealed that several boards of nursing (BONs) addressed practice issues, predominantly those related to the administration of medications or treatments. Twelve states (Arizona, Kentucky, Maine, Massachusetts, Nebraska, Ohio, South Carolina, Texas, Vermont, Virginia, West Virginia, and Wyoming) adopted or revised advisory opinions or position statements related to the administration of medications or treatments. Nine of these states (Arizona, Kentucky, Maine, Nebraska, Ohio, Texas, Vermont, Virginia, and Wyoming) focused on the administration of sedation or analgesia.

The following list covers position and practice statements, clinical practice advisories, advisory and declaratory rulings, advisory opinions, and interpretive guidelines issued or revised by BONs from September 2015 through September 2016:

\section{Alaska}

Adopted

- Licensed practical nurse (LPN) scope of practice

\section{Arizona}

Adopted

- Low-dose continuous intravenous (IV) ketamine administration for treatment of intractable or chronic pain, or depression

Revised

- Bone marrow aspiration and biopsy

- Debridement, conservative sharp wound

- Dual profession and dual health care licensure/certification

- Informed consent

- Intra-aortic balloon removal

- Intraosseous cannulation and removal

- Moderate sedation/analgesia

- Orders: accepting, transcribing, reviewing

- Peripherally inserted central catheter (PICC) insertion, suturing, maintenance, removal, and verification of tip placement

- Pulmonary artery catheter removal

\section{Connecticut}

Proposed

- Whether registered nurses can perform physical examinations for commercial driver's licenses

\section{Hawaii}

Amended

- Law to recognize the advance practice registered nurse (APRN) role to certify cause of death

- Exclusionary formulary for APRNs with prescriptive authority

- Statutes related to APRNs practicing to the fullest extent of their training and education

\section{Kentucky}

Republished

- Role of the registered nurse (RN)/LPN in spinal screening for detection of common abnormal curvatures of the spine

- Scope of nursing practice in gynecological cancer detection

- Performance of arterial puncture by registered nurses

- Roles of nurses in superficial wound closure

Revised

- Roles of nurses in the administration of medication per intraspinal routes

- Role of the RN first assistant

- Performance of wound debridement by nurses

- Role of nurses in the care of intrapartum patients

- Roles of nurses in the implementation of patient care orders

- Employment of nursing students as nursing personnel using either an academic or a "nurse extern" service model

- Roles of RNs in invasive cardiac procedures

- Roles of nurses who provide "private duty" nursing

- Application and removal of a cast by nurses and closed reduction of a fracture by APRNs

- Roles of nurses in the delivery of emergency medical care via ambulance services

- Administration of medications for procedural sedation and analgesia by nurses

- Scope of registered nursing practice in the deactivation of internal defibrillator

\section{Louisiana}

Adopted

- The RN assisting with peripheral nerve blocks

Revised

- The RN transporting critically ill neonates

\section{Maine}

Revisited

- Administration of propofol (Diprivan) by registered professional nurses

\section{Massachusetts}

Issued

- Enhancing the disclosure of unanticipated outcomes

Revised

- Use of vagal nerve stimulator magnet

- Cardiopulmonary resuscitation in long-term care facilities

- Administration of immunizing agents or vaccines

- LPN in the charge or supervisory nurse role

- Management of patients receiving analgesia by catheter technique

- Nurse practitioner as first assistant in cardiac catheterization

- Role of the licensed nurse in the Department of Public Health Medication Administration Program

\section{Minnesota}

Updated

- Joint Statement on pain management

Nebraska

Reaffirmed

- Sedation 
Revised

- Cosmetic and dermatologic procedures

\section{New Hampshire}

Updated

- RN/LPN scope of practice in nail cutting and use of a Dremel per provider assessment and order

New York
Updated
- Immunization Guidelines for Schools and Guidelines for
Medication Management in Schools

\section{North Carolina}

Created

- Telehealth/telenursing

Revised

- Accepting an assignment

- RN and LPN scope of practice: Components of nursing comparison chart

- Complementary therapies

- Death

- Infusion therapy/insertion/access procedures

- Nurse-in-charge assignment to LPN

- Physician orders: communication and implementation

- Staff development

- Staffing and patient/client safety

- Standing orders

- Title "Nurse" is protected

\section{Ohio}

Created

- $\mathrm{RN}$ role in the care of patients undergoing exercise cardiac stress testing

- RN's role in the care of patients receiving intravitreal injectable medications

- Revised

- RN filling and unfilling a patient's surgically established gastric banding system

- RN care of patients receiving IV moderate sedation for medical and/or surgical procedures

- $\mathrm{RN}$ role in emergent intubation performed by an authorized provider

- RN utilization of the Sapiens TCS or other comparable device to confirm PICC tip placement in adults

\section{Oklahoma}

Revised

- Delegation of nursing functions to unlicensed persons

- Licensure verification and photocopying of nursing licenses

- APRN certification examinations approved by the Oklahoma Board of Nursing

\section{Oregon}

Adopted

- APRNs and nonsurgical aesthetic procedures

- "Delegation Process" and "Assignment and Supervision"

- Fitness to practice: evaluation of applicants

- Provision of foot care by RNs and LPNs

Revised

- RN who participates in cosmetic procedures

- Employment requirement for certified nursing assistants and certified medication aides
- Fitness to practice: failure to disclose, lying, or falsification of applicants

- Fitness to practice: sexual misconduct

- Nurse's role in pain management

- Patient abandonment

- Scope of practice decision making guidelines for all licensed nurses

\section{South Carolina}

Formulated

- RNs performing physical examinations

Published

- Joint advisory opinion issued by the South Carolina State Boards of Medical Examiners and Nursing regarding the waiver of licensure requirements for certain professionals pursuant to designation of an emergency

- Role and scope of LPN to practice without on-site RN supervision under certain circumstances

- Role and scope of neonatal nurse practitioners and APRNs with competency based education and preparation to perform circumcisions on newborns

- Role and scope of certified nurse midwife who is out of the acute care setting to assist in the performance of a vaginal birth after Cesarean delivery

Revised

- Role and scope of a licensed nurse in a school setting to select, train, determine competency and evaluate unlicensed school personnel in the provision of treatments and the administration of medications required to meet a specific student's needs in the event that a medical emergency occurs when a licensed nurse is not readily available

- Role and scope of APRN to conduct assessments without physician collaboration or preceptors

\section{South Dakota}

Adopted

- Performance of limited diagnostic ultrasound by RNs

\section{Tennessee}

Approved

- Abandonment of patients

- Decision-making guidelines

- LPN role in physical assessment

- LPN role in IV access and infusions in peripheral lines

- LPN role in IV access and infusions in central lines

- Supervision of LPNs

- LPNs in a supervisory role

- LPN care of ventilator dependent patients in the home health setting

- Emergencies

- Reporting incompetent, unethical or illegal practice

- Skilled nursing services rendered by unlicensed personnel

Texas

Revised

- Nurses carrying out orders from physician assistants

- Role of the licensed vocational nurse (LVN) in the pronouncement of death

- Nurses with responsibility for initiating physician standing orders

- Role of the nurse in moderate sedation 
- Use of American Psychiatric Association diagnoses by LVNs, RNs, or APRNs

- Role of LVNs and RNs in school health

- RNs in the management of an unwitnessed arrest in a resident in a long term care facility

- Administration of medication \& treatments by LVNs

- LVN scope of practice

- RN scope of practice

Vermont

Accepted

- Termination of the APRN-patient relationship

Revised

- Responsibilities of the nurse in providing complementary and integrative health interventions

- Role of the nurse in the administration of homeopathic drugs, herbal medicine products, and dietary supplements

- Palliative sedation at the end of life

- Abandonment

- APRN prescribing controlled substances to immediate family member

\author{
Virginia \\ Adopted \\ - RNs and procedural sedation \\ Revised \\ - Medication administration training curriculum \\ - Information on prescriptive authority in Virginia

\section{Washington} \\ Adopted \\ - Prevention and treatment of opioid-related overdoses \\ West Virginia \\ Revised \\ - Delegation of medication administration by an APRN \\ Wyoming \\ Approved \\ - APRN practice management \\ Revised \\ - Analgesia by catheter: epidural, intrathecal, intrapleural, \\ perineural \\ - Blood transport by certified nursing assistant (CNA) \\ - CNA role \\ - CNA assistance with self-administration of medications \\ - Cosmetic \& dermatologic procedures \\ - LPN IV certified (IV-C) course requirements \\ - LPN IV-C scope of practice \\ - Medication assistant-certified (MA-C) role \\ - Moderate sedation \\ - Nitrous oxide administration \\ - Nursing interventions that may not be delegated
}

